\title{
The Early Origins of Birth Order Differences in Children's Outcomes and Parental Behavior $₫ \sigma$
}

\author{
Jee-Yeon K. Lehmann \\ Ana Nuevo-Chiquero \\ Marian Vidal-Fernandez
}

\begin{abstract}
We document birth order differences in cognitive and noncognitive outcomes and maternal behavior from birth to adolescence using the National Longitudinal Survey of Youth 1979 (NLSY79). As early as age one, later-born children score lower on cognitive tests than their siblings, and the gap increases until school entry and remains statistically significant thereafter. Variations in parental behavior, such as cognitive stimulation by mothers, can explain a large portion of the birth order differences in cognitive abilities before school entry. Our findings suggest that broad shifts in parental behavior are plausible explanations for the observed birth order differences in education and labor market outcomes.
\end{abstract}

\footnotetext{
Jee-Yeon K. Lehmann is a Manager at Analysis Group, Inc. Ana Nuevo-Chiquero is a Lecturer at the School of Economics, University of Edinburgh and an IZA Research Affiliate. Marian Vidal-Fernandez is a Senior Lecturer at the School of Economics at the University of Sydney, a Life Course Centre and an IZA Research Fellow. The authors thank two anonymous referees for their insightful comments and suggestions and acknowledge Sarah Brown, Colin Cameron, Aimee Chin, Deborah Cobb-Clark, Hilary Hoynes, Chinhui Juhn, Martin Karlsson, Kevin Lang, Shelly Lundberg, Daniele Paserman, Elaine Liu, Andy Zuppann, and seminar participants at the University of Sydney, Melbourne Institute, University of Wollongong, Purdue University, the BIG seminar at Universitat de Barcelona, Australian National University, Curtin University, University of Western Australia, Collegio Carlo Alberto, VU University Amsterdam, University of Edinburgh, Universidad Carlos III, Bristol University, University of Essex, the 35th Australian Health Economics Meetings, the 2013 ASSA Meetings, the 2013 SOLE Meeting, the 2013 EALE meetings, the 2014 RES Conference, and the 2015 Essen "Health. Skills. Education" conference for helpful comments. The views presented in this paper are those of the authors and do not necessarily reflect those of Analysis Group, Inc. or its clients. Any errors or omissions are those of the authors. The data used in this article can be obtained beginning August 2018 through August 2021 from Marian Vidal-Fernandez, University of Sydney, H04 Merewhether Building, 2006, Darlington, NSW, Australia, m.vidal-fdez@sydney.edu.au.

[Submitted August 2016; accepted August 2016]; doi:10.3368/jhr.53.1.0816-8177

ISSN 0022-166X E-ISSN 1548-8004 @ 2018 by the Board of Regents of the University of Wisconsin System $\circlearrowleft$ Supplementary materials are freely available online at: http://uwpress.wisc.edu/journals/journals/ jhr-supplementary.html

O This open access article is distributed under the terms of the CC-BY-NC-ND license (http://creative commons.org/licenses/by-nc-nd/3.0) and is freely available online at: http://jhr.uwpress.org
}

THE JOURNAL OF HUMAN RESOURCES • 53 - 1 


\section{Introduction}

A growing number of studies find that birth order affects education and labor market outcomes. Theoretically, the direction of the relation between birth order and individuals' outcomes is ambiguous. Parents and families face different temporal and financial constraints over time, which may lead to unequal distribution of inputs and resources across children. These disparities may benefit the first- and the last-born children, who tend to share family resources with fewer siblings over their lifetime (Birdsall 1991), or they may advantage later-born children, if parental earnings tend to increase significantly over time (Parish and Willis 1993). Additionally, the presence of an older or a younger sibling or changes in parental characteristics or attitudes could also contribute to changing home environments for children in the same family. For example, later-born children may receive greater cognitive stimulation or better care from older siblings and more educated parents (Zajonc 1976). However, if the level of intellectual stimulation at home is closely tied to parental time and attention, later-born children may be disadvantaged from being part of a larger family. ${ }^{1}$

Despite the theoretical ambiguity in the net effect of birth order on individuals' outcomes, most empirical studies on the effect of birth order have found a sizable and significant negative relation between higher birth order and key outcomes such as IQ, educational attainment, and wages (Behrman and Taubman 1986; Kessler 1991; Hanushek 1992; Kantarevic and Mechoulan 2006; Black, Devereux, and Salvanes 2005; Black, Devereux, and Salvanes 2007). ${ }^{2}$ Yet attempts to identify the sources of these birth order differences have not been as successful. Price (2008) and Monfardini and See (2016) investigate the role of parental time investment and find that, although parents do spend less quality time with later-born children at any given age, birth order differences in cognitive assessments cannot be explained by variations in maternal or parental quality time. Similarly, using data from the British Household Panel Survey, Booth and Kee (2009) show that later-born children have fewer books at home, but birth order differences in educational attainment are robust to controlling for variations in the availability of books. Moreover, Black, Devereux, and Salvanes (2007) find that the negative relation between birth order and IQ scores of young Norwegian adults cannot be explained by birth endowments, such as birth weight, gestational period, and head size.

\footnotetext{
1. Recently, optimal stopping or endogenous fertility models have shown that when the quality draw of the eldest child is less than expected, parents might either be less likely to have additional children or be motivated to continue having children until they reach an optimal stopping quality (Ejrnæs and Pörtner 2004). The former effect implies that earlier-born children will tend to have better outcomes, while the latter effect implies the opposite. Juhn, Rubinstein, and Zuppann (2015) use twins as an instrumental variable and panel data to control for omitted factors and find that increases in family size decrease parental investment and children's cognitive abilities.

2. For example, Black, Devereux, and Salvanes (2005) find that compared to the first-born, second-born children have about 0.3 to 0.4 fewer years of completed education, and Black, Devereux, and Salvanes (2007) find IQ differences between first-born and second-borns of about one-fifth of a standard deviation or approximately three IQ points. Ejrnæs and Pörtner (2004) and De Haan, Plug, and Rosero (2007) are important exceptions. Using data from the Philippines and Ecuador, respectively, they show that birth order is associated with a positive impact on years of completed education. Their findings suggest that the worse outcomes of laterborn individuals in developed countries (United States, United Kingdom, Australia, and Norway) cannot be simply explained by a natural, biological phenomenon that advantages the first-born, but that they may be related to systematic differences in within-family resource allocations or child-rearing practices.
} 
Although these studies show that disparities in parental time or birth endowments cannot explain birth order differences in education or labor market outcomes, some broad hints about their sources can be gleaned from recent studies on school-aged children. These studies find evidence of a negative relation between birth order and cognitive test scores administered as early as age five (Price 2008; Monfardini and See 2016; Hotz and Pantano 2015). Hotz and Pantano (2015) also show that parents are less strict with their later-born children who receive lower grades in school. The authors suggest that such a pattern is consistent with a reputation model of strategic parenting in which parents try to establish household rules by behaving more strictly with the firstborn child. However, it is unclear whether such changes in parental behavior are indeed driven by their desire to establish a reputation with their first child or whether these changes are reflective of a broader, systematic shift in attitudes, expectations, and behaviors as parents gain experience and face greater constraints on their time, attention, and resources.

In this paper, we rely on the rich data on parental behavior and children's outcomes available in the Children of the National Longitudinal Survey of the Youth 1979 (CNLSY79) to document the start and the evolution of birth order differences in cognitive and noncognitive outcomes and parental behavior from birth to start of adolescence. We show that birth order differences in cognitive abilities start as early as infancy and that changes in maternal behavior and in the quality of cognitive stimulation at home appear well before achievement differences among siblings are clearly established. We also find that systematic shifts in parental behavior and home environment are able to explain most of the birth order differences in cognitive assessments before school entry.

Specifically, estimates from a mother-fixed-effects model with a rich set of timevarying controls show that, at ages zero to three, later-born children score about 0.3 to 0.8 standard deviations lower in cognitive assessments relative to the first-born child, and these differences remain large thereafter. In contrast to popular notions about the effect of birth order on personality, we do not find strong evidence of birth order differences in noncognitive measures, except with regard to how children perceive their scholastic abilities as teenagers.

Modeling the production of cognitive achievement in children as a cumulative process that depends on both lagged and contemporaneous home inputs and a rich set of time-varying controls, we find that within-family variations in parental behavior as measured by the home environment scores in the CNLSY79 are able to explain most of the birth order differences in cognitive achievement before school entry (ages zero to five). ${ }^{3}$ Taken together, our findings suggest that a plausible explanation for the negative relation between birth order and education and employment outcomes is a broad and systematic shift in parenting attitudes and behavior from the first-born to their later-born children that starts early in children's lives. ${ }^{4}$ These changes in parental behavior-

3. In a recent study, Pavan (2016) models production of children's achievement as a function of past achievement and parental investment and show that parents' investments across sibling can account for more than one-half of the birth order effect in cognitive skills.

4. We find significant shifts in maternal behavior and attitudes from the first to her later-born children. Such differences are evident before any clear signs about child quality or incentives for strategic parenting are present. For example, compared to the pregnancy of the first child, in subsequent pregnancies, mothers are much less likely to reduce alcohol and cigarette consumption and to breastfeed after giving birth, and they are likely to delay prenatal care visits. Additionally, as early as in the first year of life, later-born children receive 
especially in the provision of active and deliberate cognitive stimulation at homeappear to set later-born children on a lower path for human capital accumulation.

To our knowledge, this paper is the first study to identify the start and the evolution of birth order effects across a wide range of cognitive and noncognitive assessments from birth to adolescence. Previous studies of birth order effects have largely focused on outcomes of either adults or school-aged children. However, assessing whether there are significant birth order differences in early development and cognitive achievement is critical for unearthing the sources of these disparities. Second, we show that there are no large or consistent differences in children's temperament or attitudes by their birth order, suggesting that broad differences in noncognitive abilities cannot explain later-born children's worse educational achievement. Third, we provide evidence of large and significant birth order differences in early parental inputs even during pregnancy and children's first year of life. Such early appearance of systematic shifts in parental behavior, attitude, and focus - before any clear signs about child quality or incentives for strategic parenting are present-suggests that parents are choosing to relax what they might deem as nonessential components of child-rearing for their later-born children. ${ }^{5}$

\section{Description of Data: NLSY79 and CNLSY79}

The National Longitudinal Survey of Youth 1979 (NLSY79) is a nationally representative sample of 12,686 men and women between 14 and 21 years old who were first interviewed in 1979. Periodic surveys of these individuals have been conducted since then, collecting rich information on employment, income, welfare program participation, education, and other background variables. Starting in 1986, 11,420 children of the 6,283 female NLSY79 respondents have been interviewed biannually, forming the CNLSY79 sample. ${ }^{6}$ The survey data on children include information on scores from cognitive and noncognitive assessments, prenatal investments, birth outcomes, early childhood health, and home environment. Together, the linked NLSY79 and CNLSY79 data provide unique and detailed longitudinal information on a large, nationally representative sample of mothers and their children. The availability of a thorough record on maternal characteristics, along with extensive data on children's prenatal and early childhood health and development indicators, make the NLSY79 Children and Young Adults an ideal dataset to explore birth order differences in cognitive-noncognitive outcomes and parental behavior.

To document the start and the evolution of birth order effects across a consistent sample of children from birth to adolescence, we make several sample restrictions. First, we restrict our estimation sample to children who were at least 14 years old at the time of the 2010 survey, the latest survey data available. This restriction ensures that we are able to track children's outcomes from birth to their early teens. Second, because we estimate

\footnotetext{
lower levels of cognitive stimulation at home despite receiving the same quality of emotional support from their parents.

5. Our finding that parents provide the same level of emotional support to all their children but lower levels of active cognitive stimulation is consistent with such an interpretation.

6. Some children born before or in 1972 never belonged to the CNLSY79, because once they turn 15 years old, they leave the sample and start the NLSY79 Young Adults survey, which resembles the NLSY79 questionnaire.
} 


\section{Table 1}

Main Sample Descriptive Statistics

\begin{tabular}{lcccc}
\hline & & & Within & \\
& & & $\begin{array}{c}\text { Family } \\
\text { Standard }\end{array}$ & $N$ \\
Variable & Mean & $\begin{array}{c}\text { Standard } \\
\text { Deviation }\end{array}$ & $\begin{array}{c}\text { Station } \\
\text { Deviation }\end{array}$ & (Children) \\
\hline Family size & 2.691 & 0.783 & & 4850 \\
Birth order & & & & \\
$\quad$ First-born & 0.439 & 0.496 & 0.376 & 4850 \\
$\quad$ Second-born & 0.385 & 0.487 & 0.385 & 4850 \\
$\quad$ Third-born & 0.144 & 0.351 & 0.180 & 4850 \\
$\quad$ Fourth-born & 0.031 & 0.174 & 0.042 & 4850 \\
Mother's race & & & & \\
$\quad$ White & 0.788 & 0.408 & & 4850 \\
$\quad$ Black & 0.147 & 0.354 & & 4850 \\
$\quad$ Hispanic & 0.065 & 0.246 & & 4850 \\
Male & 0.521 & 0.500 & 0.259 & 4850 \\
Age of mother (at birth) & 24.843 & 4.714 & 1.978 & 4850 \\
Mother's highest grade & 12.716 & 2.189 & 0.075 & 4850 \\
$\quad$ completed (at birth) & & & & \\
Father figure present in & 0.617 & 0.486 & 0.232 & 4850 \\
$\quad$ household (age 0-2) & & & & \\
Age difference with previous sibling & 2.034 & 2.573 & 1.529 & 4850 \\
Age difference with eldest sibling & 2.684 & 3.413 & 1.978 & 4850 \\
First boy born in family & 0.350 & 0.477 & 0.325 & 4850 \\
\hline
\end{tabular}

Notes: Means are weighted to account for oversampling of minorities.

a mother-fixed-effects model, we necessarily drop all children without siblings in our dataset. Third, we remove families with more than four kids or with twin births because families that are atypically large or with twins may face systematically different constraints or environments. ${ }^{7}$ Fourth, we drop military families and the oversample of low-income whites who were not surveyed after 1990 for budget issues. Fifth, to assess changes in parental behavior among children for whom we see early outcome differences, we restrict our sample to those children with nonmissing pre- and postnatal input information of interest and two key control variables at birth: mother's education and an indicator for father's presence. Finally, to test for birth order differences in both cognitive and noncognitive outcomes within a consistent sample, we restrict our sample to children with nonmissing cognitive and noncognitive test

7. Our pooled results (for instance, nonstratified by family size), however, do not change with the inclusion of larger families or twins. 
indexes before the age of $15 .^{8}$ Together, these restrictions yield a sample size of 4,850 children in our main estimation sample. ${ }^{9}$

Table 1 describes our main estimation sample. The average mother in our sample has about 2.7 children. About 43 percent of the children in our sample are first-born, 39 percent are second, 14 percent third, and only 3 percent of children are born fourth. Children born to White mothers constitute the majority of our sample; the remaining 15 percent and 6 percent of children are born to Black and Hispanic mothers, respectively. At the time of children's birth, mothers in our sample are, on average, about 25 years old and have completed high school. About 60 percent of children have a father figure in the home at some point during their first three years of life. The children in our sample are born about two years apart. Thirty-five percent of the children in our sample are first-born boys in the family. ${ }^{10}$

\section{Empirical Strategy}

\section{A. Construction of Cognitive and Noncognitive Summary Indexes}

\section{Problems with multiple inference}

Although the CNLSY79 provides longitudinal data on a wide range of cognitive and noncognitive outcomes, restricting our sample to children with nonmissing information on the entire set of outcomes across all survey waves would severely limit our sample size and reduce the statistical power of our tests for birth order effects. Furthermore, examining a large number of outcomes across several age groups can lead to the problem of multiple inference (that is, overrejection probability of the null-hypothesis [type I error] increases as additional outcomes are analyzed, even in the absence of a true effect). ${ }^{11}$ Consequently, we rely on summary index tests, the empirical strategy employed in Kling, Liebman, and Katz (2007); Anderson (2008); and Deming (2009). Summary index tests have been shown to be robust to problems of multiple inference; the probability of a false rejection does not increase when new outcomes are added to the index. In addition, summary index tests have the advantage of providing a more powerful test of birth order effects that mitigates problems associated with measurement error, especially in small samples (Anderson 2008).

We construct indexes of cognitive and noncognitive abilities by first normalizing each test score to have a mean of zero and a standard deviation of one in our main estimation sample. Next, we appropriately reverse the signs of outcomes for which higher scores indicate worse outcomes, such that all tests have the same directional interpretation.

\footnotetext{
8. Section IIIA provides a detailed description of how these indexes are constructed.

9. To balance the need for a consistent sample of children across time with the need for statistical power, we do not restrict our sample to children with nonmissing information for all of the outcomes that we examine in a given age group of assessment. Qualitative results and the magnitudes of estimates are similar when the sample is restricted to children with nonmissing assessment scores or HOME scores across all age groups and assessments. These results are available upon request.

10. These basic characteristics of our sample are similar to those of the 5 percent sample of the National Vital Statistics data after the same restrictions on family sizes are imposed.

11. See Romano and Wolf (2005) for a theoretical analysis of the issue and Anderson (2008) for an example of how multiple inference can lead to overrejection of the null hypothesis.
} 
Finally, we take a simple average of all the relevant normalized outcomes to construct a summary index of cognitive assessments and another summary index for noncognitive assessments.

\section{Cognitive summary index}

We construct a summary index of cognitive abilities from birth to age 14 by relying on three different test scores: (i) the Motor and Social Development Score (MSD), (ii) the Peabody Picture Vocabulary Test (PPVT), and (iii) Peabody Individual Achievement Test-Mathematics (PIAT-M) and Reading (PIAT-R). All assessments have been used extensively in a myriad of studies evaluating the cognitive development of young children. $^{12}$

First, developed by the National Center for Health Statistics to measure motor, social, and cognitive development of young children from birth to age three, the MSD is based on the mother's answers to 15 or 16 age-appropriate questions about her child's development. All questions on the MSD have dichotomous answers, and these "yes" or "no" responses are summed to create the MSD scale. MSD scores have been shown to be strongly associated with cognitive test scores later in life (Mott 1991). ${ }^{13}$ Second, the PPVT is a vocabulary test administered to children between the ages of three and 14 and is widely recognized to be a good measure of cognitive ability, especially of verbal intelligence. It has been found to be highly correlated with scores on other intelligence tests and is viewed to be an important indicator of early and middle school outcomes (Baker, Keck, Mott, and Quinlan 1993). Third, the PIAT-R: Reading Recognition assesses skills such as matching letters, naming names, and reading single words aloud. ${ }^{14}$ PIAT-M, the counterpart for mathematical skills, assesses the knowledge and application of mathematical concepts and facts. Both PIAT-R and PIAT-M are administered to children between five and 14 years old. Because math and reading tests may assess different types of cognitive abilities, we also construct an alternative cognitive index excluding PIAT-M scores to determine whether birth order effects are more or less prominent in verbal abilities relative to mathematical abilities.

\section{Noncognitive summary index}

The cognitive tests described above provide important measures of children's early development and achievement. However, by themselves, they may fail to capture critical dimensions of children's overall mental and social development (Heckman, Stixrud,

12. Descriptions of the cognitive and noncognitive assessments, prenatal and postnatal inputs, and early home environment are drawn from the NLSY79 Child and Young Adult Data online guides available at: http://www .nlsinfo.org/childya/nlsdocs/guide/topicalTOC.html.

13. Some examples of the questions on the MSD include "Child rolled over alone on purpose" (0-3 months), "Child has pulled to standing position with no help" (4-6 months), "Child knows names of common objects" (7-9 months), "Child says words other than mama/dada" (10-12 months), "Child has said names of at least 4 colors" (19-21 months).

14. PIAT-R: Reading Comprehension measures the child's ability to derive meaning from sentences that are read silently. However, because the reading comprehension portion of the PIAT-R test was only administered to children scoring above a certain threshold on the reading recognition portion, we choose to focus on PIAT-R: Reading Recognition. 
and Urzua 2006). To investigate whether there are birth order differences in noncognitive outcomes from ages zero to 14 , we focus on three assessments available in the CNLSY79: (i) Difficult Temperament Index (DTI), (ii) Behavior Problem Index (BPI), and (iii) Self-Perception Profile for Children (SPPC).

First, DTI is a measure of personality and social adjustment of children in early childhood. ${ }^{15}$ The DTI is based on temperament scales that are designed to assess the child's usual behavior in areas such as activity level, attachment styles, compliance, or sociability. Ten different scores measure various dimensions of temperament between ages zero and six, although not all scores are appropriate for all ages. ${ }^{16}$ The DTI is constructed by averaging the scores available for each age, with a higher index score indicating a more difficult temperament. Second, the BPI measures the incidence and the severity of behavioral problems in children four years and older. In our analysis, we examine the BPI Total Score, which is based on the mother's responses to 28 questions regarding specific behaviors that her children may have exhibited in the previous three months. Higher BPI indicates presence of greater behavioral problems.

Third, the SPPC is a measure of the child's sense of general self-worth and selfcompetence based on self-reported answers to the interviewer's verbal questions. The overall score is divided into two subscores: a scholastic competence score and a global self-worth score. For each test item/question, the child is given a choice to select the former or the latter part of a two-part statement that best describes him or her and a rating that measures the extent to which the description is true for them. ${ }^{17}$ The SPPC was completed by children eight years and older in the survey years 1986 to 1994, and beginning in 1996, the assessment was limited to children who were 12 years and older.

\section{B. Empirical Specifications}

We exploit the linked mother-child structure of the NLSY79-CNLSY79 and rely on a mother-fixed-effects model to measure the effect of birth order on early inputs and outcomes. First, we estimate the following equation:

(1) $Y_{\text {iafrc }}=\sum_{k=2}^{4} \beta_{k}[\text { Birth Order }=k]_{\text {iafrc }}+\gamma X_{\text {iafrc }}+\kappa_{a}+v_{f}+\eta_{r}+\xi_{c}+\varepsilon_{\text {iafrc }}$

where $i$ denotes child, $a$ age at assessment, $f$ family, $r$ region, and $c$ birth cohort. $Y_{\text {iafrc }}$ is the outcome of interest. Our baseline specification also controls for child-specific characteristics $X_{\text {iafrc }}$ that may affect mother's choices and children's outcomes: gender,

15. We choose to focus on DTI rather than other subindexes available for the same age group — compliance and attachment - because the difficult temperament index relies on responses from the most number of questions addressed on the temperament survey. We have, however, created the noncognitive summary index using compliance and attachment indexes. Our results are robust to the inclusion of these different temperament indexes.

16. The temperament scales were adapted from Rothbart's Infant Behavior Questionnaire and Kagan's compliance scale, measured by a set of age-appropriate, maternal report items and interviewer ratings. Description of the questionnaire items are available at: http://www.nlsinfo.org/content/cohorts/nlsy79 -children/topical-guide/assessments/temperament-how-my-child-usually-acts.

17. For example, a description on the SPPC survey states, "Some kids feel like they are just as smart as other kids their ages, but other kids aren't so sure and wonder if they are as smart." 
age of the mother at birth and its quadratic, and age difference from his/her oldest and precedent siblings. ${ }^{18} \kappa_{a}, v_{f}, \eta_{r}$, and $\xi_{c}$ are child's age at assessment-, mother-, regional-, and birth cohort-fixed effects, respectively. The coefficient $\beta_{k}$ captures difference in the outcome of interest between the $k$ th born child and his/her first-born sibling at the same age $a$. In alternative specifications, we estimate Equation 1 separately for families with completed sizes of two, three, and four children to investigate whether birth order effects change with family size.

We also take advantage of the panel structure of the CNLSY79 to investigate how birth order effects change from birth to adolescence. Hence, we estimate Equation 1 separately by age group, each spanning three to four years. All estimates are weighted to account for the oversampling of minorities, and standard errors are clustered at the mother level to account for within-family correlation in error terms as in De Haan, Plug, and Rosero (2014) and Buckles and Kolka (2014).

Although mother-fixed-effect models account for the impact of unobserved, timeinvariant mother and family characteristics on outcomes, there may be time-varying covariates such as mother's employment status, education, and paternal presence that may contribute to sibling outcome differences. Because time-varying family-level covariates may be endogenously determined along with child outcomes, our baseline specification does not include them as controls. However, throughout the paper, we also present results from mother-fixed-effects models with additional controls for family income at the time of birth, average lifetime family income (measured as the average annual family income from birth to the time of assessment), family size at the time of assessment, maternal employment status the year after birth (employed, unemployed, out of labor force, or in active force), mother's highest grade completed at child's birth, and an indicator for the presence of a father figure in the household during the child's first three years of life.

\section{Birth Order Differences in Cognitive and Noncognitive Outcomes}

\section{A. Adult Outcomes}

To begin our study of birth order differences in early cognitive and noncognitive outcomes, we first examine variations in several important adult outcomes in our main estimation sample. Because individuals in the CNLSY79 are still relatively young, we further restrict the sample to individuals who were at least 20 years old in 2010 (or 22 when we analyze years of completed education) - the last survey year observed in our data - to minimize any bias from right-censoring of data. In Table 2, we report results on high school graduation, years of completed education, and likelihood of criminal activity and teenage childbearing. ${ }^{19}$ For each outcome, we first present results from an ordinary least squares (OLS) specification without mother-fixed effects, followed by our main model with mother-fixed effects.

18. Buckles and Munnich (2012) report a significant and positive effect of birth spacing on educational achievement of the oldest sibling. Nonetheless, results are robust to the exclusion of this variable.

19. Criminal activity is defined as a variable that takes a value of one if ever convicted, been on probation, sentenced by a judge or in prison, and zero otherwise; teenage childbearing indicator is only defined for women. 


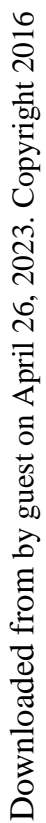

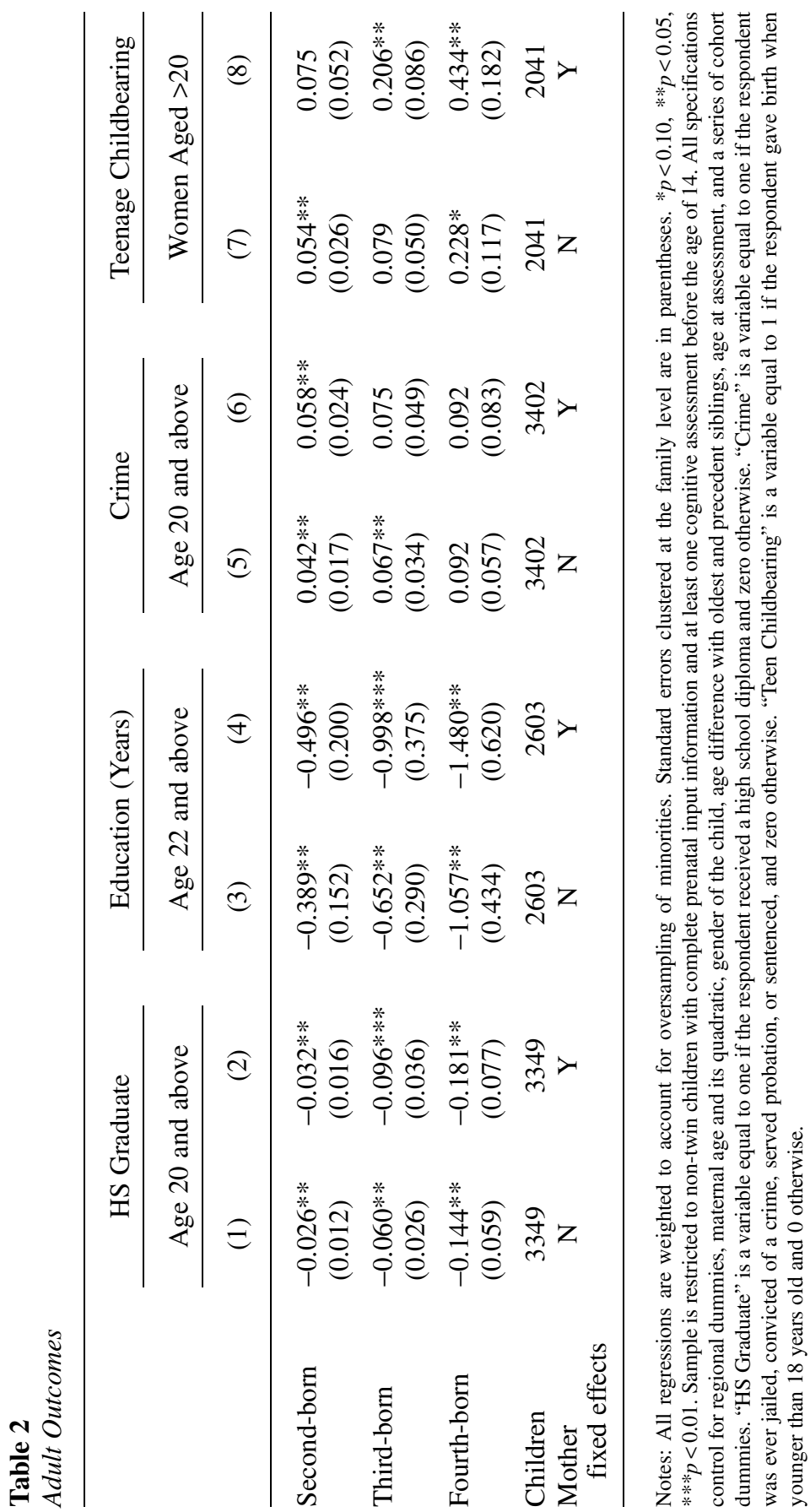


Consistent with previous findings in the United States and in other developed countries, higher birth order is associated with lower likelihood of high school graduation and fewer years of completed education. Compared to the first-borns, secondborns are approximately 3 percentage points (or 0.17 standard deviations) less likely to be a high school graduate and complete about 0.5 fewer years (or 0.22 standard deviations) of education. Higher birth order individuals have worse outcomes still; compared to the first-born, third- and fourth-borns are 10 and 18 percentage points less likely to graduate high school and complete about 1 to 1.5 fewer years of education. The magnitudes of these birth order effects on educational attainment are comparable to the effects reported in Kantarevic and Mechoulan (2006) on the basis of data from the Panel Study of Income Dynamics.

We also examine the likelihood of criminal activity and teenage motherhood. Columns 5 and 6 show that individuals of higher birth order are also more likely to be involved in a criminal activity, with later-borns about 6 to 8 percentage points more likely to have been ever jailed, convicted of a crime, served probation, or sentenced compared to the first-born. As shown in Columns 7 and 8 , we also find a positive relation between higher birth order and the likelihood of giving birth as a teen, consistent with Black, Devereux, and Salvanes (2005).

\section{B. Birth Order Differences in Cognitive and Noncognitive Outcomes}

In sum, Table 2 indicates that higher birth order is associated with worse educational and social outcomes as adults in our estimation sample. To determine the start of such birth order effects, we turn our attention to children's early outcomes and assess how differences in cognitive and noncognitive test scores evolve over time. Tables 3 and 4 report our findings on birth order differences in cognitive and noncognitive summary indexes. ${ }^{20}$ In Table 3, Column 1 and Columns 2 through 4 present results from models with and without mother-fixed effects, respectively, pooling all family sizes together. Columns 5 to 7 stratify results from the mother-fixed-effects model with a full set of controls by completed family size.

The top panel of Table 3 presents estimates of birth order effects in our cognitive index. Column 1, the simple OLS model without mother-fixed effects (but with additional controls for mother's religion, race, and completed family size), shows that second-born children score about 0.16 standard deviations lower on cognitive assessments compared to the first-born. Third- and fourth-born children perform worse, scoring about 0.2 standard deviations lower than the first-born. Inclusion of mother-fixed effects in Column 2 yields slightly larger birth order effect sizes, especially for the third- and fourth-born children, whose cognitive assessment scores are about 0.25 to 0.34 standard deviations lower than their eldest sibling. ${ }^{21}$ As shown in Columns 3 and 4, these motherfixed-effects estimates are robust to the addition of time-varying controls for maternal

20. For both cognitive and noncognitive indexes, around 70 percent of the variation is within family, allowing for a precise estimation of our fixed-effects estimates.

21. As in Black, Devereux, and Salvanes (2005) and De Haan, Plug, and Rosero (2014), the mother-fixedeffects estimates are of similar order of magnitude to those from the OLS model without fixed effects. This suggests that birth order differences are not simply the product of unobserved variation in (time-invariant) family characteristics. 


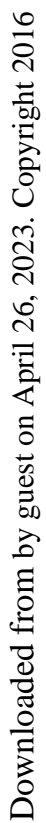

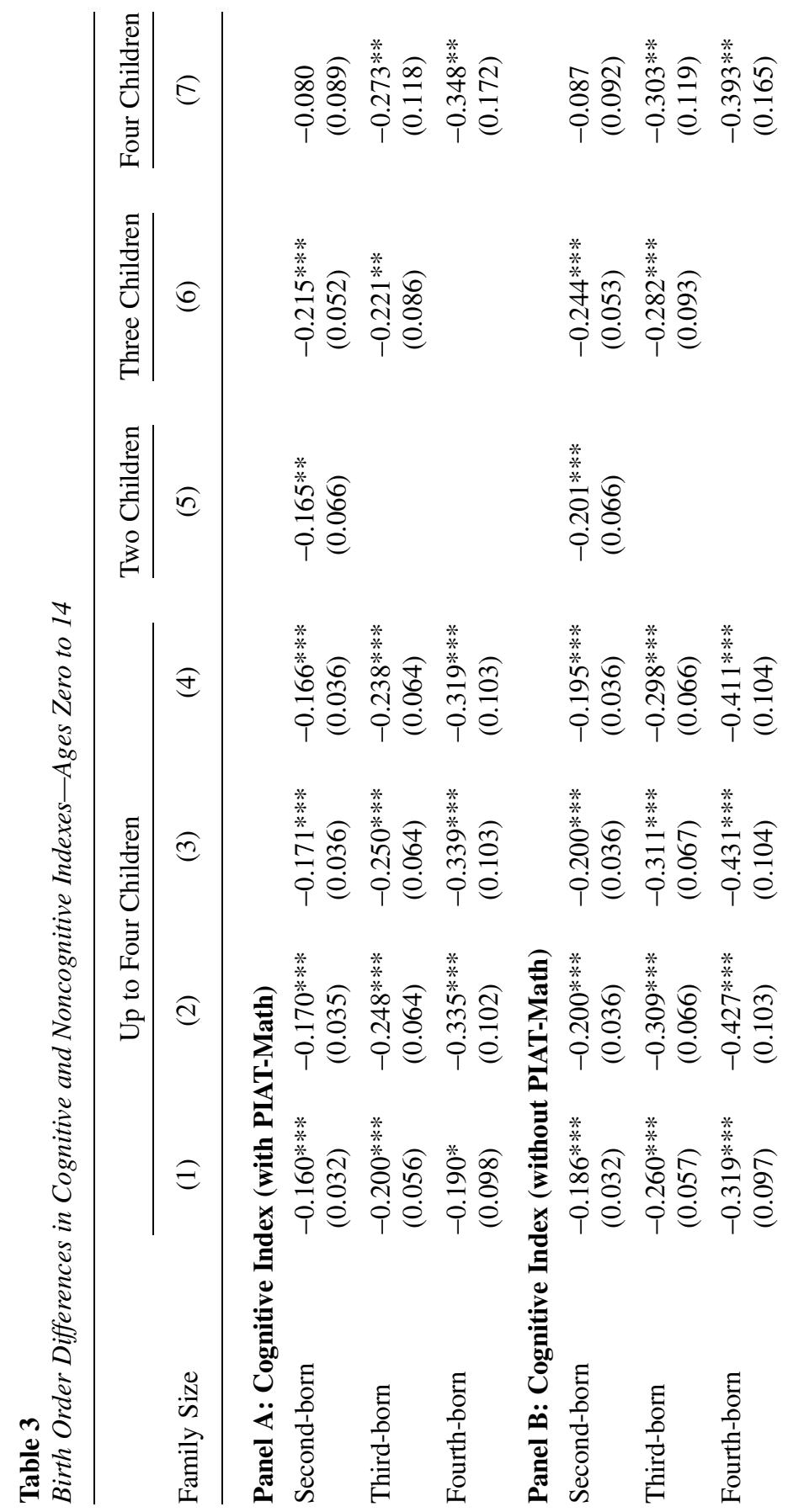




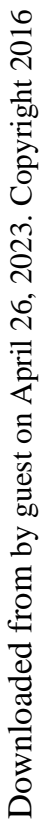

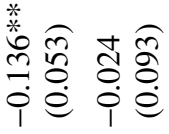

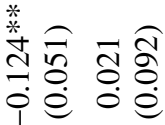

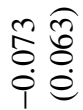

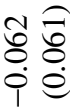

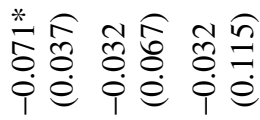

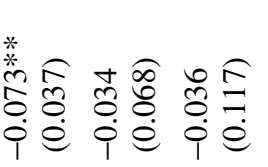

:

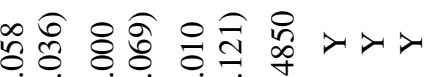

i $\dot{0}$ i

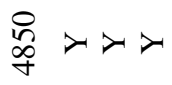

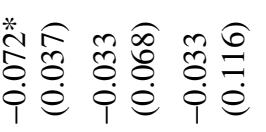

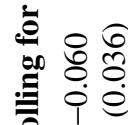

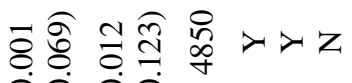

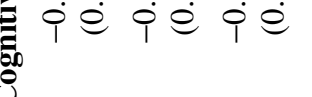

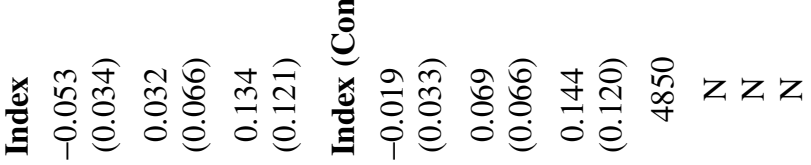

:

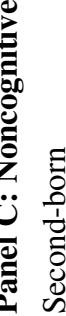

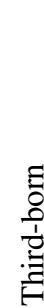

E̊ำ

薝

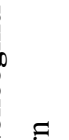

E

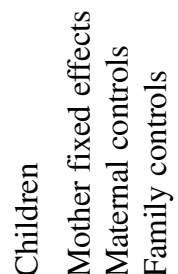

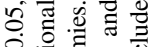

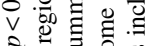

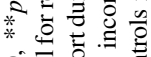

$\circ$ 응 귱

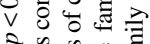

*

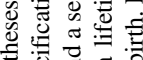

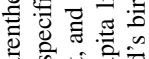

है

$\Xi \leftleftarrows \begin{gathered}0 \\ 0 \\ 0\end{gathered}$

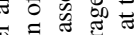

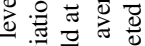

흥 웡

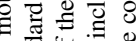

记

क ज $\approx$ ज

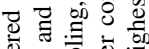

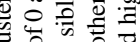

을 흘

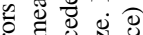

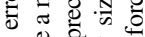

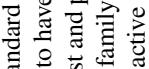

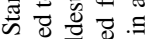

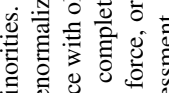

当氜

पे

$\exists \geq 0$ प

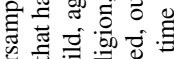

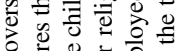

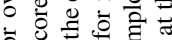

한

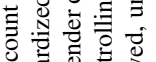

可

음.

उ)

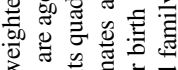

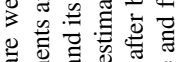

ส

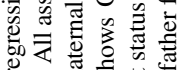

远和志严

安家

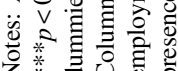


Table 4

Birth Order Differences in Cognitive and Noncognitive Indexes-Age Groups

\begin{tabular}{ccccc} 
& $0-3$ & $4-6$ & $7-10$ & $11-14$ \\
Ages & $(1)$ & $(2)$ & $(3)$ & (4) \\
\hline
\end{tabular}

\section{Panel A: Cognitive Index (with PIAT-Math)}

$\begin{array}{lllll}\text { Second-born } & -0.311 * * * & -0.144 * * * & -0.101 * * & -0.194 * * * \\ & (0.086) & (0.055) & (0.044) & (0.051) \\ \text { Third-born } & -0.500 * * * & -0.213 * * & -0.138 * & -0.342 * * * \\ & (0.176) & (0.104) & (0.082) & (0.103) \\ \text { Fourth-born } & -0.888 * * * & -0.189 & -0.160 & -0.558 * * * \\ & (0.275) & (0.169) & (0.144) & (0.183)\end{array}$

Panel B: Cognitive Index (without PIAT-Math)

$\begin{array}{lllll}\text { Second-born } & -0.294 * * * & -0.169 * * * & -0.148 * * * & -0.225 * * * \\ & (0.082) & (0.055) & (0.046) & (0.057) \\ \text { Third-born } & -0.472 * * * & -0.235^{* *} & -0.236 * * * & -0.455^{* * *} \\ & (0.166) & (0.105) & (0.088) & (0.118) \\ \text { Fourth-born } & -0.838 * * * & -0.256 & -0.269 * & -0.802 * * * \\ & (0.260) & (0.183) & (0.142) & (0.202)\end{array}$

Panel C: Noncognitive Index

$\begin{array}{lcccc}\text { Second-born } & -0.369 & 0.012 & -0.088^{*} & -0.131^{* *} \\ & (0.226) & (0.069) & (0.051) & (0.051) \\ \text { Third-born } & -0.382 & 0.130 & -0.061 & -0.171^{*} \\ & (0.470) & (0.121) & (0.103) & (0.097) \\ \text { Fourth-born } & -0.607 & 0.265 & -0.090 & -0.253 \\ & (0.720) & (0.215) & (0.181) & (0.175)\end{array}$

Panel D: Noncognitive Index (Controlling for Cognitive Index)

\begin{tabular}{lcccc} 
Second-born & -0.323 & -0.021 & -0.082 & $-0.088^{*}$ \\
& $(0.246)$ & $(0.074)$ & $(0.052)$ & $(0.049)$ \\
Third-born & -0.408 & 0.080 & -0.044 & -0.086 \\
& $(0.515)$ & $(0.128)$ & $(0.107)$ & $(0.092)$ \\
Fourth-born & -0.700 & 0.125 & -0.076 & -0.102 \\
& $(0.781)$ & $(0.221)$ & $(0.190)$ & $(0.169)$ \\
Children & 2470 & 3859 & 4232 & 3885 \\
Mother fixed effects & $\mathrm{Y}$ & $\mathrm{Y}$ & $\mathrm{Y}$ & $\mathrm{Y}$ \\
Maternal controls & $\mathrm{Y}$ & $\mathrm{Y}$ & $\mathrm{Y}$ & $\mathrm{Y}$ \\
Family controls & $\mathrm{Y}$ & $\mathrm{Y}$ & $\mathrm{Y}$ & $\mathrm{Y}$ \\
\hline
\end{tabular}

Notes: All regressions are weighted to account for oversampling of minorities. Standard errors clustered at the mother level in parentheses. $* p<0.10$, $* * p<0.05$, *** $p<0.01$. All assessments are age-standardized scores that have been renormalized to have a mean of 0 and a standard deviation of 1 . All specifications control for regional dummies, maternal age and its quadratic, gender of the child, age difference with oldest and precedent sibling, age of the child at assessment, family size at assessment, and a series of cohort dummies. Mother controls include average per capita lifetime family income and employment status year after birth (employed, unemployed, out of labor force, or in active force) and highest grade completed at the child's birth. Family controls include presence of father figure and family size measured at the time of the assessment. 
characteristics, presence of father figure, family income, and family size at the time of assessment. Finally, Columns 5 to 7 stratify the results from the mother-fixed-effects model with the full set of controls by family size. We do not find significant differences in birth order effects across family sizes, except in the case of second-borns in families with four children. However, the coefficient is still negative, and the lack of statistical significance at conventional levels may be driven by the small number of families in our sample with four children. The robustness of birth order effects to variations in family size is consistent with the findings in Black, Devereux, and Salvanes (2005) and others.

The second panel in Table 3 reports birth order effect estimates for an alternative cognitive index that excludes the PIAT-Math score. Birth order effects are slightly larger than in the previous panel, with second-born children scoring about 0.2 standard deviations lower and third- and fourth-born scoring 0.3 to 0.43 standard deviations lower than the first-born on cognitive assessments. As before, these results are robust to the inclusion of various time-varying maternal and family controls and similar across different family sizes.

In contrast to the large birth order effects found in the cognitive index, we do not find evidence of systematic differences in noncognitive assessments by birth order. The third panel of Table 3 shows that, across various sets of time-varying controls, there are neither large nor statistically significant birth order effects in noncognitive assessments, except for a mild negative effect on second-born children. Results are similar when they are stratified by family size. ${ }^{22}$ Finally, the bottom panel includes the cognitive index as a control when estimating birth order effects in the noncognitive index. Recall that one component of the noncognitive summary index is a measure of one's perceptions about his/her scholastic abilities (SPPC-Scholastic). Therefore, failing to account for systematic variations in cognitive abilities may bias our estimates of birth order effects in noncognitive assessments. As expected, accounting for differences in cognitive abilities reduces the point estimates slightly, and any effects previously observed for secondborns are no longer statistically significant, except in families with four children.

Next, we investigate the evolution of birth order differences over time from birth to adolescence. Table 4 presents our results on cognitive and noncognitive indexes by age group. To ensure sufficient number of observations within each cell, we first classify ages in four groups: ages zero to three, four to six, seven to ten, and 11 to 14. Equation 1 is then estimated separately for every age group. All columns include mother-fixed effects and the full set of time-varying maternal characteristics, father presence, and family income and size controls. ${ }^{23}$

We find strong evidence of birth order effects in cognitive abilities across all age groups. Even in the first three years of life, higher birth order is associated with worse performance on cognitive assessments. At ages zero to three, second-born children score about 0.3 standard deviations lower on cognitive assessments than the first-born. Compared to their eldest sibling, third- and fourth-born children perform worse still, scoring about 0.5 to 0.9 standard deviations lower on cognitive assessments than their eldest sibling. The magnitudes of these birth order effects are similar in the cognitive index with and without PIAT-Math scores.

22. However, we observe a larger effect for second-born children in families of three.

23. Our results are robust to a more parsimonious specification excluding these time-varying controls. 
The start of schooling appears to attenuate these differences in cognitive achievement. At ages four to six, second- and third-borns score about 0.14 to 0.24 standard deviations lower on cognitive tests relative to first-borns. The magnitudes of these differences are similar at ages seven to ten. However, by ages 11 to 14 , birth order differences reach similar levels observed at ages zero to three, especially when PIAT-Math test scores are excluded from the cognitive index. The two left panels of Figure A.1 in the Online Appendix show the age group trends birth order effects and their corresponding 95percent confidence intervals. $^{24}$

In contrast, we do not observe strong age trends in birth order effects in noncognitive outcomes. These results are presented in the third and fourth panels of Table 4 and in the right panel of Figure A.1. ${ }^{25}$ At ages zero to three, although differences in noncognitive assessments between the first-borns and later-borns are fairly large, we cannot reject the null that they are equal to zero at conventional levels. The birth order effect sizes fall dramatically after school entry and remain small and statistically insignificant up to the start of adolescence, especially when the cognitive index is included as a control.

Examination of individual assessments that comprise the noncognitive summary index at each age group provides some additional insight into these findings. Tables A.1 and A.2 in the Online Appendix show birth order differences in the Difficult Temperament Index, the Behavior Problem Index, and the Self-Perception Profile for Children, separately. After accounting for time-varying family characteristics, we find little evidence of birth order differences in temperament or behavioral problems. Nonetheless, estimates for young children are imprecisely estimated, which suggests a complex relation between birth order and noncognitive skills during early childhood. On the other hand, self-perception measures are significantly associated with birth order. First-born children consistently report better perception of themselves, particularly when asked about their academic performance. These differences in self-perception, especially of their own academic abilities, account for most of the birth order effects in noncognitive assessments in older children. In contrast, individuals of different birth order exhibit similar levels of behavioral problems during their early teen years.

In summary, results in Tables 3 and 4 (and corresponding tables and figures in the Online Appendix) reveal several important findings. First, there is a strong negative relation between birth order and cognitive outcomes of children. On average, each unit increase in birth order is associated with approximately a 0.17 standard deviation decline in cognitive test scores from birth to age 14. The magnitudes of these birth order effects are substantial, but are consistent with previous research on birth order effects (Hotz and Pantano 2015). To place these birth order effect sizes in a broader context, we can compare them to estimates of the black and white gap in cognitive test scores found in the same data. Lang and Sepulveda (2007) find black-and-white differences in cognitive test ranging from 0.2 to 0.5 standard deviations after controlling for a myriad of mother and family controls, including mother's AFQT, parental interactions and the home environment score, pregnancy and early life history, and family structure. Similarly, Fryer and Levitt (2004) report a black-white gap in the PIAT-Reading scores of

24. These magnitudes are similar to Hotz and Pantano (2015) who report that first-born children score 0.15 to 0.2 standard deviations higher than younger siblings at ages ten to 14 .

25. To the extent that noncognitive assessments administered at varying ages measure different sets of noncognitive abilities, any observation about time trends in the noncognitive index may be limited. 
0.3 to 0.4 standard deviations at grade five. Based on estimates from Fryer and Levitt (2004) and our birth order effect sizes at ages seven to ten in the cognitive index without the PIAT-Math scores, we calculate that the gap between the first- and the second-born is about 40 to 50 percent of the black-white gap. The gap between the firstand third-born is approximately 60 to 80 percent of the estimated black-white gap in cognitive test scores.

Second, we find neither a strong nor consistent effect of birth order on noncognitive outcomes. Given strong belief in popular culture regarding the influence of birth order on one's personal and social development, the absence of birth order effects in temperament, for instance, may be surprising. However, our finding is consistent with recent research in psychology that relies on robust, within-family analysis to estimate the impact of birth order on personality or noncognitive abilities. ${ }^{26}$ However, there is one area in which birth order is strongly associated with scores on noncognitive assessments: individual's self-perception of their scholastic competence. Even conditional on having the same cognitive test scores, later-born children have worse perceptions about their scholastic abilities. Studies in psychology and education show a statistical significant correlation between measures of scholastic self-worth at adolescence and future educational attainment (Ross and Broh 2000). These systematic differences in how children of different birth order view their academic abilities may be a channel through which birth order differences in early cognitive achievement and home environments impact adult outcomes.

Third, birth order effects in cognitive test scores are slightly larger when excluding math scores. Using the American Time Use Survey, Hofferth (2009) shows that parents spend considerably more time reading with their children than studying any particular subject at home. Consequently, specific mathematical skills are more likely to be acquired in the classroom than at home, suggesting that the negative relation between birth order and cognitive assessment scores is likely related to differences in home environments and parental investment.

Finally, later-born children perform worse on cognitive assessments from a very early age. Even in the first three years of life, higher birth order is associated with lower scores on developmental indicators. Hence, such early appearance of birth order effects, together with our finding that school entry mitigates these effects, suggest that early shifts in parental behavior and investment are plausible explanations for birth order differences in cognitive achievement after school entry and other future outcomes.

\section{Birth Order Differences in Early Parental Behavior and Home Environment}

Motivated by our finding that large birth order differences in cognitive assessments appear as early as in the first year of life and that these gaps widen over time until primary school entrance, we investigate whether there are corresponding patterns

26. See Bleske-Rechek and Kelley (2014) and references therein. Bleske-Rechek and Kelley (2014) find weak to no impact of birth order on temperament. 
of disparities in parental behavior and home environments that can explain these early differences in cognitive development. ${ }^{27}$

\section{A. Early Prenatal and Postnatal Parental Behavior}

In this section, we present evidence of significant shifts in maternal behavior toward the first-born and later-born children, well before clear incentives for strategic parenting or strong signals about children's cognitive abilities are present. Table 5 reports birth order differences in maternal behavior and decisions during pregnancy and in the months following the child's birth. Columns 1 and 5 present the baseline OLS results, while Columns 2 to 4 and 6 to 8 present mother-fixed-effect estimates with varying sets of time-varying controls.

Examining maternal behavior during pregnancy, we find evidence that mothers become more lenient about following strict health guidelines for fetal health. First, we examine mother's alcohol consumption during pregnancy. Restricting our sample to those who had consumed alcohol during the 12 months prior to every birth, we show in the first panel (Columns 5-8) that mothers are less likely to reduce their alcohol intake during their later pregnancies (compared to their prepregnancy consumption levels). ${ }^{28}$ Compared to their pregnancy with the first-born child, mothers are 11 percentage points less likely to have reduced their alcohol consumption during their pregnancy with the second-born and around 21 percentage points less likely during their pregnancy with the third-born child.

Unfortunately, we do not have information on the timing or the size of the reduction. It is important to note that a lower likelihood of reduction does not necessarily imply higher consumption of alcohol during pregnancy. For example, women could have reduced their consumption of alcohol during their first pregnancy, which could have led to lower levels of alcohol intake before their second pregnancy. Thus, during their pregnancy with the second child, there may have been less scope for reduction in alcohol consumption. As shown in Columns 1 through 4, we do not find differences in the average number of alcoholic drinks consumed per month across their pregnancies. ${ }^{29}$

27. Consistent with previous literature (Buckles and Kolka 2014, Brenøe and Molitor 2015), we find no evidence of higher birth order children being born disadvantaged developmentally. We find similar results when using a 5 percent sample of the NVS. Both sets of results are available in the Online Appendix (Tables A.3 and A.4). Note that these findings do not imply that prenatal conditions and investments do not play a role in explaining birth order effects; rather, effects of these prenatal environments may be latent until later in life.

28. For every pregnancy, women are asked the following question: "Did you drink/smoke any alcoholic beverages/tobacco cigarettes during the 12 months before the child was born?" Women who answered affirmatively are further asked whether they reduced their alcohol/smoking consumption during pregnancy and how much did they consume. Given that these answers are given in a categorical form, we impute a median units of alcohol/cigarettes for each of the options. For alcohol the options are: never (imputed as 0 units of alcohol), less than once a month (imputed as 0.5 units of alcohol), about once a month (one unit), three to four days a month (3.5 units), one to two days a week (six units), three to four days a week (14 units), nearly every day (20 units) or every day (30 units). For cigarettes, the possible answers (and our imputed number of cigarettes) are: none, less than one pack a day (10 cigarettes), one or more pack but less than two (30 cigarettes), two or more packs a day (40 cigarettes).

29. The number of alcoholic drinks consumed during pregnancy is only reported in categorical ranges. This reporting format masks any variation within each category of consumption, which may be one reason why we do not observe differences in the number of drinks consumed across pregnancies. In addition, we are unable to control for the amount of alcohol consumption before pregnancy because this information is not available in the 
0
0
0
0
00
0
0
0
0
0
0
0
0
0
0
0
0
0
0
0
0
0
0
0
0
0
0
0
0
0
0
0
0

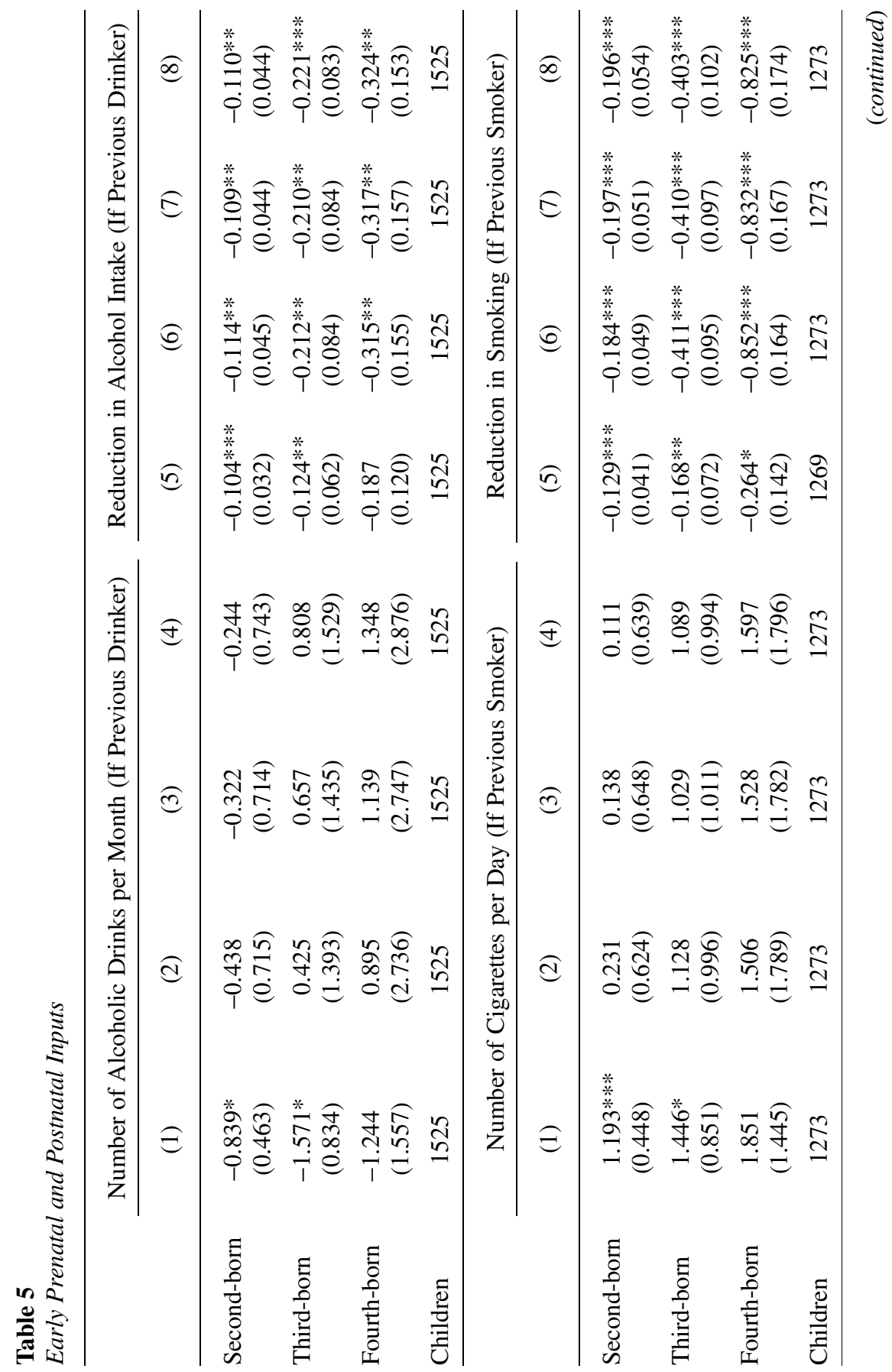




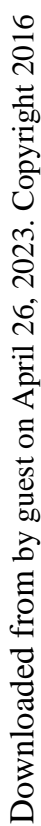

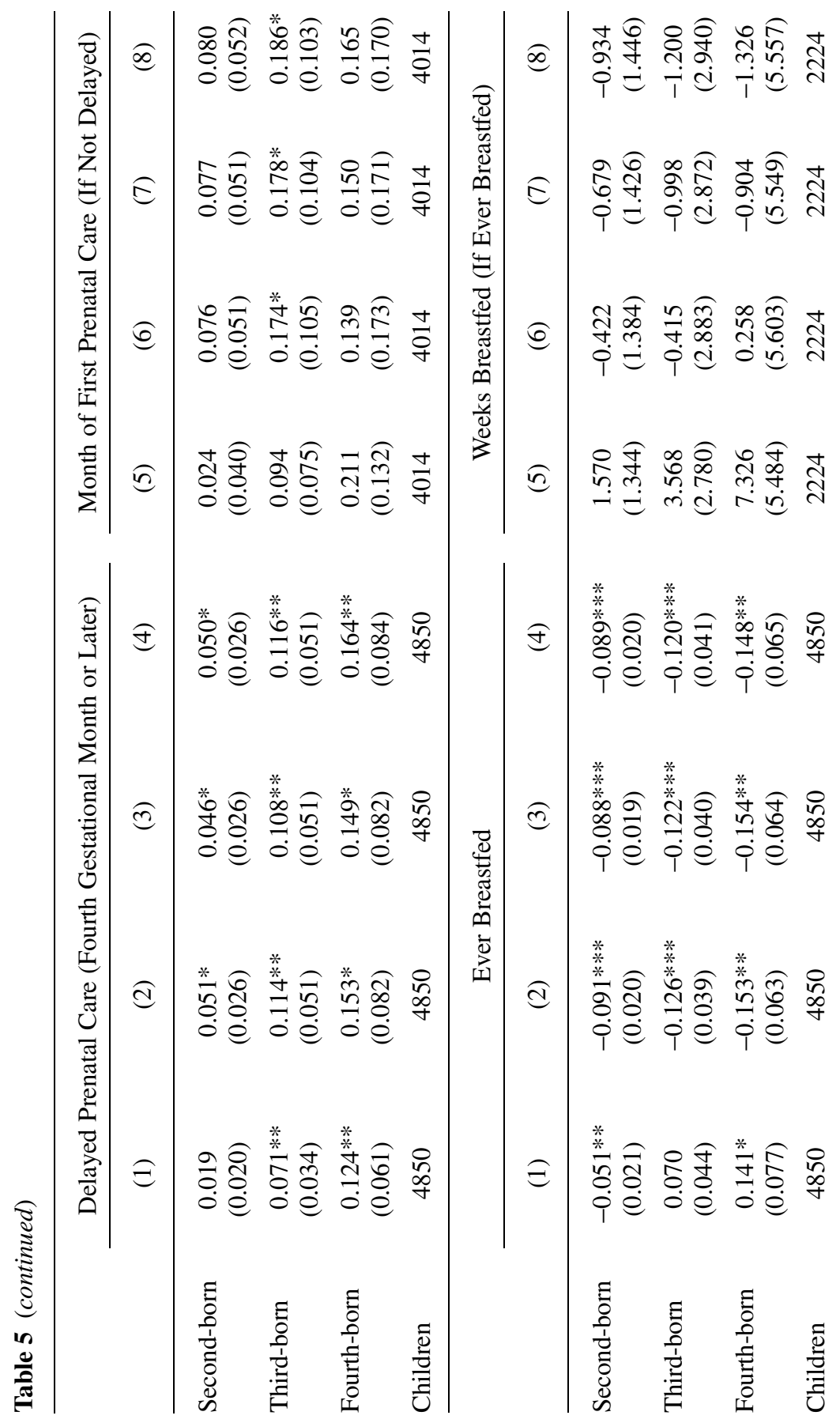




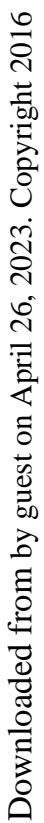

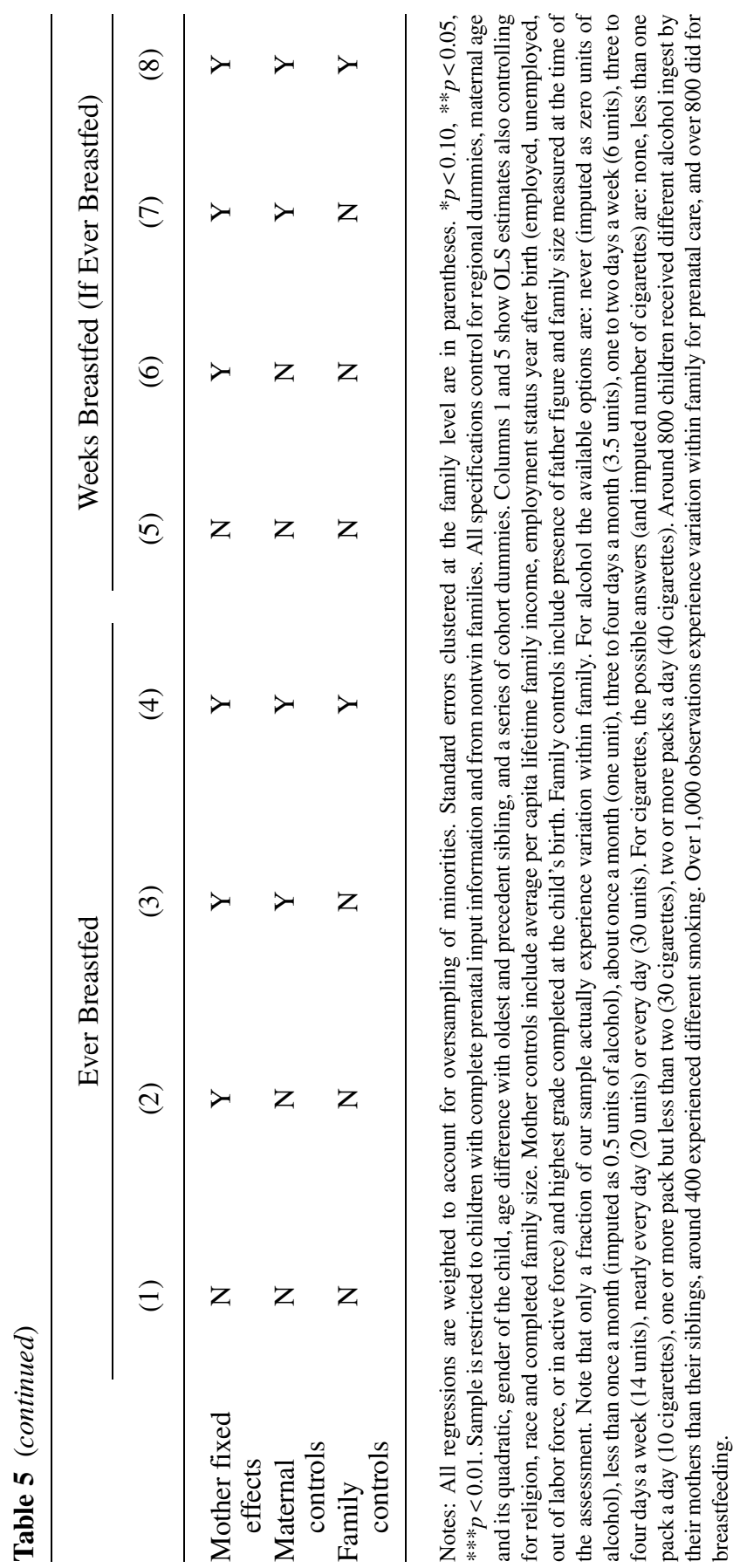


As shown in the second panel of Table 5, we find similar patterns in smoking reductions and in the number of cigarettes smoked during pregnancy by birth order.

Note that because we restrict our sample to women who drank alcohol or smoked cigarettes 12 months before each birth, we systematically select those who decided not to quit alcohol or smoking after each pregnancy. In contrast to our finding, Brenøe and Molitor (2015) report that for children born in Denmark between 1981 and 2010, women are more likely to have smoked during their first pregnancy than their later ones. Although we cannot rule out that differences between our finding and that of Brenøe and Molitor (2015) are due to the sample selection criteria imposed by our data, these differences could also be explained by variations in the timing of quitting across pregnancies. For example, using administrative data from Norway, Black, Devereux, and Salvanes (2015) find that although women are more likely to have smoked at the beginning of their first pregnancy, they are also less likely to have smoked at the end of their first pregnancy compared to their later pregnancies. Hence, overall, they are more likely to have reduced their smoking during the first pregnancy than during the later ones. Notwithstanding these caveats, because most of the births in our data occurred between 1980 and 1994 when the negative effects of smoking or heavy drinking during pregnancy were already well established, these differences in mothers' willingness to strictly follow these medical recommendations suggest a systematic shift in maternal attitude and behavior toward their first child and to their later-born children.

In the third panel of Table 5, we also find evidence that women tend to delay seeking prenatal care in their second and later pregnancies. Compared to their pregnancy with the first child, women are 5 percentage points more likely to postpone their first prenatal visit until their fourth month of pregnancy with the second child and about 11 percentage points more likely for their pregnancy with the third child. These differences are reflected in the timing of their first prenatal visit, even among those who do not delay their visit beyond the third month of pregnancy. ${ }^{30}$ Although prior experience with pregnancy could help identify and manage subsequent pregnancies better, women tend to postpone their care. While we do not see a significant effect for the second-born, mothers delay seeking prenatal care by about a week during their pregnancy with the third child. ${ }^{31}$ Our results are in line with Brenøe and Molitor (2015), who find that women in Denmark seek out a lower number of prenatal visits during their later pregnancies.

Given our data limitations, we corroborate our findings in the general U.S. population using data from the National Vital Statistics (NVS), which contain a 5 percent random sample of the entire universe of U.S. pregnant women (see Table A.5 in the Online

data. Similarly, although we do not find differences in the average number of cigarettes smoked among women who were smokers during the 12 months prior to each birth, they are much less likely to curb their smoking habits during the later pregnancies, by 20 percentage points per pregnancy, on average. Fingerhut, Kleinman and Kendrick (1990) report a relapse ratio of 70 percent within a year of birth in the mid 1980s.

30. Most women in the sample get a prenatal check within the first trimester. Thus, it is likely that women perceive the cost of delaying prenatal care to be higher once they have reached their second trimester. Hence, we restrict the sample to those who choose not to delay beyond the first trimester to assess whether differences exist even among women who choose to seek "timely" care.

31. The absence of statistically significant differences may be due to the relatively small size of our sample. Using a larger sample of birth certificates, Lewis, Mathews, and Heuser (1996) report a positive correlation between delayed prenatal care and subsequent pregnancies after the second live birth. 
Appendix). Compared to their pregnancy with the first child, women are more likely to have smoked during their later pregnancies. The results on alcohol use are slightly weaker in the NVS data, which may be due to the fact that we cannot restrict our sample to mothers who were regular drinkers before their pregnancy. The NVS also indicates that women are more likely to delay seeking prenatal care with their later pregnancies.

The bottom panel of Table 5 provides results on breastfeeding, a key maternal choice variable after birth. Our estimates show that women are less likely to breastfeed their later-born children, although if they choose to breastfeed, there are no differences in the duration. Our finding is consistent with recent studies in the United States (Buckles and Kolka 2014) and in Norway (Black, Devereux, and Salvanes 2015). Compared to the first-born, women are about 9 percentage points less likely to breastfeed their secondborn child and about 12 to 15 percentage points less likely to breastfeed the third or the fourth child. These results are robust to dropping the sample of women who breastfed for a very short time (a week or less) and did not continue afterwards. ${ }^{32}$ Moreover, the results are also robust to controlling for maternal employment and education (Column 3) and the presence of a father figure and variations in family income at the time of birth (Column 4).

The causal effect of early prenatal care on later outcomes of children is not well established, ${ }^{33}$ and there is debate about the risks associated with moderate alcohol consumption during pregnancy. ${ }^{34}$ In addition, studies showing that breastfeeding, when compared to formula-feeding, is associated with better early health and cognitive outcomes $^{35}$ are contested by findings in more recent literature showing only moderate to zero benefit to breastfeeding, depending on the statistical methods used to mitigate the problem of selection in the choice to breastfeed. ${ }^{36}$ However, although direct effects of these maternal choices are unclear, these systematic differences in prenatal and postnatal maternal behavior by birth order suggest an early and broad shifts in maternal attitudes and investments towards the first child and their later-born children.

\section{B. Early Home Environment for Cognitive Stimulation and Emotional Support}

These changes in maternal/parental behavior towards children of higher birth order are not limited to pregnancy or early life. We rely on information about children's home

32. Rates of breastfeeding increased steadily from 1970s in the United States. We control for cohort effects in all of our specifications. Moreover, changing attitudes about the benefits of breastfeeding in medicine or in society should bias us against finding a negative relation between rates of breastfeeding and birth order.

33. Currie and Grogger (2002) and others report that for normal pregnancies, a delay of one week in first prenatal visit is associated with a decrease of 1 to 1.2 ounces in birth weight.

34. See, for instance, Skogerbø et al. (2012) and Kilburn et al. (2015).

35. For example, see Belfield and Kelly (2010), Oddy et al. (2003), and Horwood and Fergusson (1998). Note that none of these studies analyze data from a randomized controlled study or utilize a natural experiment in the choice to breastfeed. All of the studies attempt to mitigate the problem of selection in the choice to breastfeed by including a large set of controls on family or child characteristics or performing propensity score matching using these sets of controls.

36. For example, see Rothstein (2013). Rothstein (2013) uses three different longitudinal U.S. datasets to investigate the impact of breastfeeding on children's early cognitive outcomes. She finds that breastfeeding for six months or more is associated with about one-tenth of a standard deviation increase in cognitive test scores when using propensity score matching methods. However, within-sibling results estimates do not show any statistically significant impact of breastfeeding. 
environment available in the CNLSY79-the Home Observation Measurement of the Environment (HOME) scores - to show that these changes in parenting styles are broad and persistent. The HOME scores have been used widely in economic and child development literature to proxy for the level and the quality of parental investment, and these scores have been shown to be significant correlates of later cognitive achievement, health, and noncognitive development (Todd and Wolpin 2007; Fryer and Levitt 2004; Cunha and Heckman 2008).

We focus on the total score as well as the two subscores summarizing the level and the quality of cognitive stimulation and emotional support in the household. The HOME questionnaire is divided into four parts to accommodate different children's needs across age groups. It includes age-appropriate questions about whether the mother reads to the child or helps with homework; availability of toys, books, or musical instruments; interaction with parents; parental attentiveness; discipline patterns; and frequency of outings. ${ }^{37}$ Responses to these questions are either given by the mother or recorded by an official home visitor, and the composite HOME scores are reported as simple summations of the scores from individual items in the questionnaire, with higher scores signifying a better home environment. To facilitate clearer interpretation, we normalize the HOME scores to have a mean of zero and a standard deviation of one. ${ }^{38}$ Because HOME scores are missing for a large fraction of children in our main estimating sample, the sample size with nonmissing HOME scores decreases considerably (from 4,850 to 2,632). In Table 6, we report estimates of birth order differences in home environments from age 0 to 14 only for those children with nonmissing observations for all age groups. However, results in which we replace a missing score with zero, with the age-specific mean of our estimating sample, or with imputed scores using maternal characteristics while controlling for indicators of missing are not significantly different from those reported in Table 6.

The first column in Table 6 presents OLS estimates. Columns 2 to 4 present fixedeffects estimates with different sets of controls, and Columns 5 to 7 stratify the results by family size for the fixed-effects specification with the full set of controls. The top panel reports estimates for the composite score, while the middle and bottom panels show results for cognitive and emotional subscores, respectively. Compared to the first-born, total home environment scores for the second-born children are lower by about 0.12 standard deviations and for the third-born by about 0.13 standard deviations when controlling for maternal covariates, father figure presence, and family income and size at the time of assessment. These results are similar when stratified by family size. ${ }^{39}$

As shown in the second and the third panel, birth order effect sizes in the cognitive subscore are larger than in the emotional subscore, suggesting that differences in cognitive stimulation are driving variations in the overall home environment across children of different birth order. The cognitive HOME subscore for the second child is 0.16 standard deviations lower than the first-born, and this difference increases to 0.21 standard deviations for the third child. On the other hand, differences in emotional

37. A detailed description of the items and its coding can be found at https://www.nlsinfo.org/content/cohorts /nlsy79-children/other-documentation/codebook-supplement/appendix-home-sf-scales.

38. Within-family variation accounts for around 65 percent of the variation in these measures.

39. Although estimates for families with four children are imprecise, the point estimates are still negative and the magnitudes are similar to those in the nonstratified sample. 


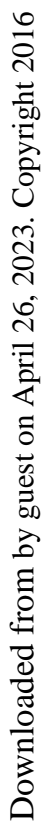

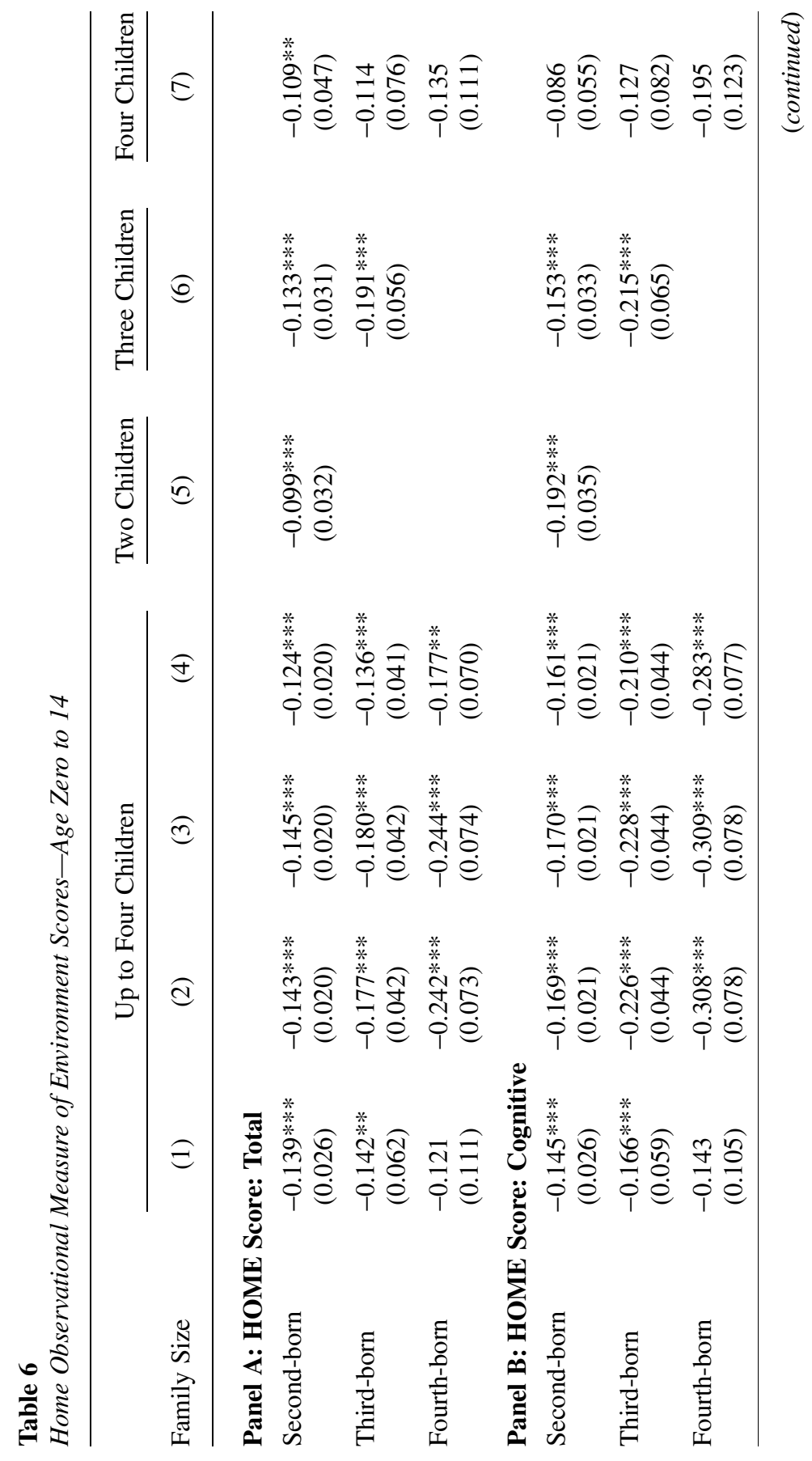




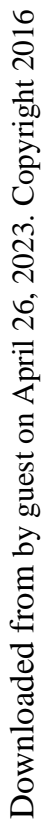

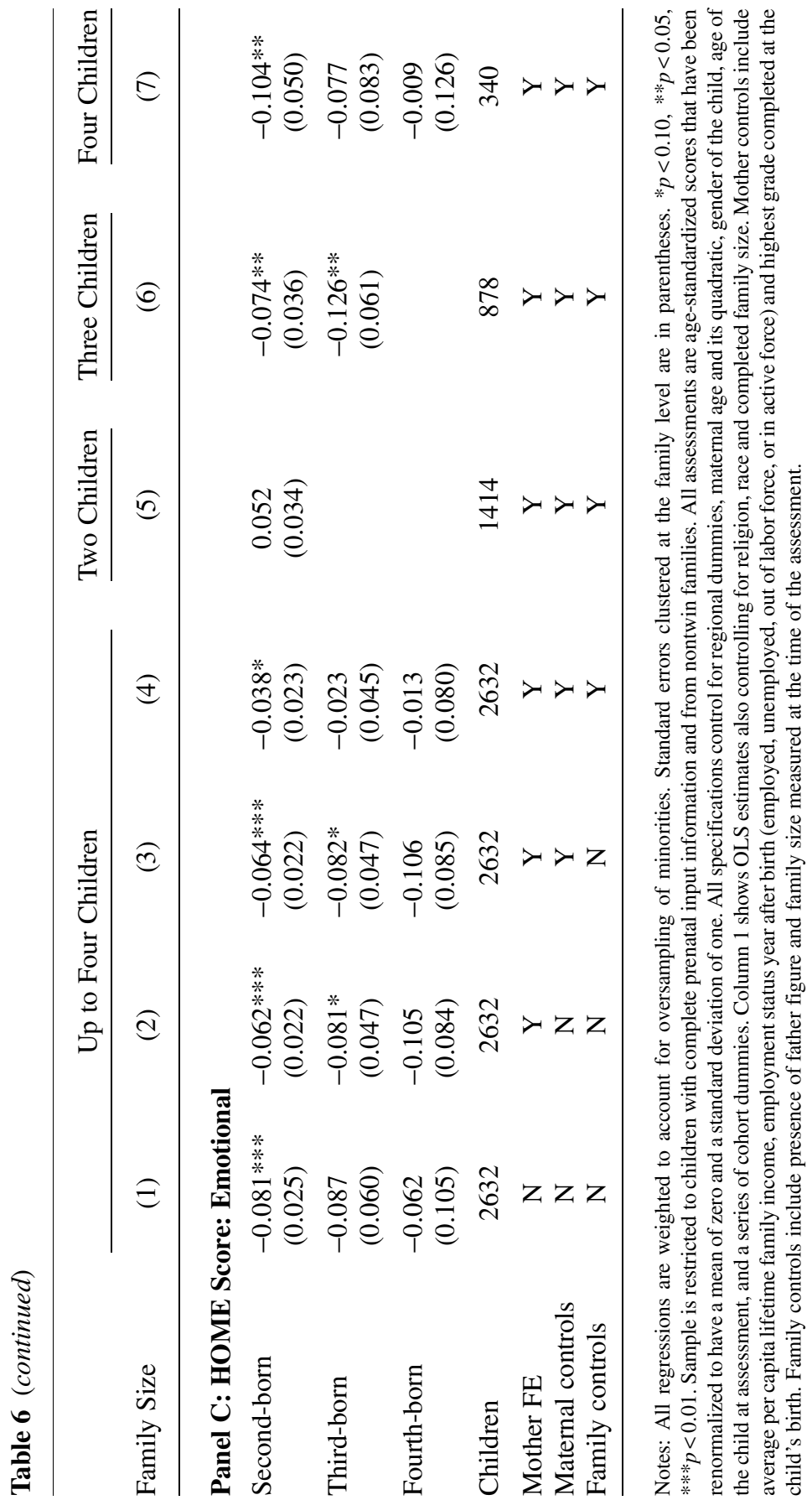




\section{Table 7}

Home Observational Measure of Environment Scores-Age Groups

$0-4 \quad 5-9 \quad 10-14$
Ages
(1)
(2)
(3)

\section{Panel A: HOME Score: Total}

$\begin{array}{lccc}\text { Second-born } & -0.080 * & -0.073 * * & -0.182 * * * \\ \text { Third-born } & (0.046) & (0.029) & (0.034) \\ & 0.054 & -0.053 & -0.272 * * * \\ \text { Fourth-born } & (0.091) & (0.063) & (0.069) \\ & 0.180 & -0.047 & -0.414 * * * \\ & (0.160) & (0.111) & (0.136)\end{array}$

\section{Panel B: HOME Score: Cognitive}

$\begin{array}{lccc}\text { Second-born } & -0.152 * * * & -0.113 * * * & -0.192 * * * \\ & (0.047) & (0.031) & (0.034) \\ \text { Third-born } & -0.104 & -0.081 & -0.331^{* * *} \\ & (0.093) & (0.068) & (0.065) \\ \text { Fourth-born } & -0.119 & -0.054 & -0.490 * * * \\ & (0.158) & (0.118) & (0.122)\end{array}$

\section{Panel C: HOME Score: Emotional}

\begin{tabular}{lccc} 
Second-born & 0.001 & 0.021 & $-0.116^{* * *}$ \\
Third-born & $(0.053)$ & $(0.037)$ & $(0.044)$ \\
& 0.108 & 0.017 & -0.093 \\
Fourth-born & $(0.109)$ & $(0.080)$ & $(0.091)$ \\
& 0.227 & 0.059 & -0.145 \\
Children & $(0.194)$ & $(0.132)$ & $(0.166)$ \\
Mother fixed effects & 2289 & 2479 & 2187 \\
Maternal controls & $\mathrm{Y}$ & $\mathrm{Y}$ & $\mathrm{Y}$ \\
Family controls & $\mathrm{Y}$ & $\mathrm{Y}$ & $\mathrm{Y}$ \\
\hline
\end{tabular}

Notes: All regressions are weighted to account for oversampling of minorities and include family fixed effects. Standard errors clustered at the family level are in parentheses. $* p<0.10, * * p<0.05$, $* * * p<0.01$. Sample is restricted to children with complete prenatal input information and from nontwin families. All assessments are age-standardized scores that have been renormalized to have a mean of zero and a standard deviation of one. All specifications control for regional dummies, maternal age and its quadratic, gender of the child, age of the child at assessment, family size at assessment, and a series of cohort dummies. Mother controls include average per capita lifetime family income and employment status year after birth (employed, unemployed, out of labor force, or in active force) and highest grade completed at the child's birth. Family controls include presence of father figure and family size measured at the time of the assessment. 
support HOME scores are substantially smaller: 0.04 standard deviations between the first- and the second-born, on average. When stratified by family size, we do not observe any differences in emotional support scores in families with two children; differences reappear in larger families.

To assess how these differences in HOME scores evolve over time, we estimate Equation 1 separately by age group. Given our sample size limitations, we rely on three age groups rather than four: ages zero to four, five to nine, and ten to 14 . These results are presented in Table 7. Even with higher demand in our data, we find evidence of lower HOME scores for children of higher birth order even at very early ages, particularly in cognitive stimulation. During the first four years of life, a second-born child's HOME scores are about 0.1 standard deviations lower than for the first child. These differences are larger for cognitive stimulation scores. In contrast, the bottom panel shows no evidence of young children receiving worse emotional support from parents. The negative relationship between birth order and cognitive stimulation increases substantially by age ten to 14 . Age trends in birth order effects in total HOME scores and subscores are presented in Figure A.2 in the Online Appendix.

These results are consistent with our finding of significant birth order differences in cognitive test scores and the absence of strong and consistent birth order effects in noncognitive assessments, except those related to self-perception of scholastic abilities. Although parents tend to provide similar levels of emotional support for all their children - what many parents would deem to be the most essential part of child rearing - they are unable to provide the same level of cognitive stimulation for their later-born children. Examining individual items that make up the cognitive subscore of the HOME inventory at ages zero to five, we find that parents spend less time reading to their later-born children, are less likely to provide appropriate toys or activities for the child, and spend less time teaching basic concepts (for example, numbers, alphabet, colors, and shapes) at home. ${ }^{40}$

\section{Early Inputs and Birth Order Differences in Cognitive Outcomes}

In the previous two sections, we have shown that (i) birth order differences in cognitive achievement start from very early in life, and (ii) there are broad changes in parental behavior during pregnancy and in the early cognitive environment parents provide at home. We now ask whether these parenting differences as measured by home environment scores and early parental behaviors can explain a significant portion of the differences in cognitive outcomes across children of different birth order.

Following Todd and Wolpin (2007), we model the production of cognitive skills as a cumulative process that depends on both lagged and contemporaneous home inputs. ${ }^{41}$

40. Our results are also robust to dropping items that do not directly involve parent-child interactions, such as the availability of books or musical instruments. Results are available upon request.

41. Parent may invest more (or less) in children with worse initial endowments to reduce (or to reinforce) differences across siblings. To assess the potential impact of such behavior on our estimates, we ask whether 
Specifically, we estimate the following model where $Y_{\text {ifrca }}$ is the cognitive test summary index observed for individual $i$ in family $f$ in region $r$ in birth cohort $c$ at age $a$ :

$$
\begin{aligned}
Y_{i f r c a}= & \sum_{k=1}^{4} \beta_{k}[\text { Birth Order }=k]_{i f r c a}+\gamma X_{i f r c a}+\delta_{a} Z_{i f r c a}+\delta_{a-1} Z_{i f r c a-1} \\
& +\delta_{a-2} Z_{i f r c a-2}+\kappa_{a}+v_{f}+\gamma_{r}+\xi_{c}+\varepsilon_{i f r c a}
\end{aligned}
$$

$X_{\text {ifrca }}$ is the complete set of the time-varying covariates we included in Table 3: maternal age, education, and employment controls; age difference; presence of father figure; birth and lifetime average family income; and family size at time of assessment. $Z_{\text {ifrca }}$ are the home environment subscores (cognitive stimulation and emotional support), and $Z_{\text {ifrca-1 }}$ and $Z_{i f r c a-2}$ are the lagged subscores. ${ }^{42}$ As before, $\kappa_{a}$ are child's age of assessment fixed effects, $v_{f}$ are family (mother) fixed effects, $\gamma_{r}$ regional fixed effects, and $\xi_{c}$ birth cohort fixed effects.

Table 8 presents our results. For comparison, Column 1 reports the same estimates of birth order effects in the cognitive index from Tables 3 and 4, controlling for our full set of time-varying maternal controls, presence of father figure, and family income (Column 4 in Table 3 and four columns from the first panel in Table 4). The remaining columns in Table 8 include controls for birth outcomes, maternal prenatal behavior and breastfeeding choices, and home environment scores and their two-period lagged scores, respectively. As shown in Column 2, including birth outcomes has minimal impact on the estimated birth order effects in cognitive outcomes. This finding is not surprising given our results in Table A.3 in the Online Appendix, which indicated that later-born children do not appear to be born disadvantaged developmentally. Similarly, controlling for variations in prenatal and early maternal behavior in Column 3 has no impact on birth order effects in the pooled specification (top panel) and only a marginal impact when stratified by age group.

parental investment behavior (as measured by HOME scores) are significantly different in families with "large" differences in the initial measure of "quality" between the first and second child compared to families with "small" differences in these initial quality measures. Given that cognitive assessment scores may be impacted by potential parental compensatory and/or reinforcing behavior, we rely on the earliest cognitive assessment available in the CNLSY79 (Motor and Social Development (MSD) scores at zero to one years) and birth weight as measures of initial child quality. Precisely, we define families with "large" differences in initial quality as those families in which MSD scores at zero to one years for the first and second children are at least one standard deviation apart. In the presence of compensatory (reinforcement) behavior, parents would invest more (less) in second children with the largest differences in initial "quality" from the first-born. However, we do not find evidence that birth order differences in HOME scores are different between families with large differences in initial quality and those with smaller differences. The same results hold for families with large and small differences in birth weights. These results suggest that our birth order effects findings cannot be simply explained by parent's compensatory or reinforcing behavior. In addition, we have shown that women tend to underinvest in later-born children even during pregnancy, before they know the quality of child.

42. We limit our lag to two periods to keep the sample of children consistent with the estimating sample in Table 3. Because the CNLSY79 is administered biannually, the contemporaneous HOME scores and its twoperiod lags cover a period of about six years for a typical child in the sample. As we noted in the previous section, HOME scores are missing for a large fraction of the children in our main estimating sample. We replace missing scores with zero and control for indicators of missing scores. Restricting the analysis to a sample composed only of children with complete HOME score information yields very similar point estimates, but as a result of the small sample size, we lose precision in our estimates. 


\section{Table 8}

Inputs and Birth Order Differences in Cognitive Summary Index
(1)
(2)
(3)

(4)

\begin{tabular}{|c|c|c|c|c|}
\hline \multicolumn{5}{|l|}{ All ages } \\
\hline Second-born & $\begin{array}{c}-0.166 * * * \\
(0.036)\end{array}$ & $\begin{array}{c}-0.170 * * * \\
(0.036)\end{array}$ & $\begin{array}{c}-0.158 * * * \\
(0.036)\end{array}$ & $\begin{array}{c}-0.094 * * \\
(0.042)\end{array}$ \\
\hline Third-born & $\begin{array}{c}-0.238 * * * \\
(0.064)\end{array}$ & $\begin{array}{c}-0.236 * * * \\
(0.064)\end{array}$ & $\begin{array}{c}-0.227 * * * \\
(0.064)\end{array}$ & $\begin{array}{c}-0.154 * * \\
(0.070)\end{array}$ \\
\hline Fourth-born & $\begin{array}{c}-0.319 * * * \\
(0.103)\end{array}$ & $\begin{array}{c}-0.307 * * * \\
(0.103)\end{array}$ & $\begin{array}{c}-0.308 * * * \\
(0.103)\end{array}$ & $\begin{array}{c}-0.216 * \\
(0.117)\end{array}$ \\
\hline Children & 4850 & 4850 & 4850 & 4850 \\
\hline \multicolumn{5}{|l|}{ Ages 0-3 } \\
\hline Second-born & $\begin{array}{c}-0.311 * * * \\
(0.086)\end{array}$ & $\begin{array}{c}-0.309 * * * \\
(0.087)\end{array}$ & $\begin{array}{c}-0.292 * * * \\
(0.086)\end{array}$ & $\begin{array}{c}0.006 \\
(0.209)\end{array}$ \\
\hline Third-born & $\begin{array}{c}-0.500 * * * \\
(0.176)\end{array}$ & $\begin{array}{c}-0.486 * * * \\
(0.175)\end{array}$ & $\begin{array}{c}-0.474 * * * \\
(0.176)\end{array}$ & $\begin{array}{c}0.269 \\
(0.348)\end{array}$ \\
\hline Fourth-born & $\begin{array}{c}-0.888 * * * \\
(0.275)\end{array}$ & $\begin{array}{c}-0.850 * * * \\
(0.276)\end{array}$ & $\begin{array}{c}-0.858 * * * \\
(0.276)\end{array}$ & $\begin{array}{c}0.214 \\
(0.478)\end{array}$ \\
\hline Children & 2470 & 2470 & 2470 & 2470 \\
\hline \multicolumn{5}{|l|}{ Ages 4-6 } \\
\hline Second-born & $\begin{array}{c}-0.144 * * * \\
(0.055)\end{array}$ & $\begin{array}{c}-0.116 \\
(0.071)\end{array}$ & $\begin{array}{c}-0.127 * \\
(0.071)\end{array}$ & $\begin{array}{c}-0.126 * \\
(0.070)\end{array}$ \\
\hline Third-born & $\begin{array}{c}-0.213 * * \\
(0.104)\end{array}$ & $\begin{array}{c}-0.174 \\
(0.120)\end{array}$ & $\begin{array}{c}-0.194 \\
(0.119)\end{array}$ & $\begin{array}{c}-0.177 \\
(0.118)\end{array}$ \\
\hline Fourth-born & $\begin{array}{c}-0.189 \\
(0.169)\end{array}$ & $\begin{array}{c}-0.146 \\
(0.180)\end{array}$ & $\begin{array}{c}-0.172 \\
(0.177)\end{array}$ & $\begin{array}{c}-0.178 \\
(0.182)\end{array}$ \\
\hline Children & 3859 & 3859 & 3859 & 3859 \\
\hline \multicolumn{5}{|l|}{ Ages $7-10$} \\
\hline Second-born & $\begin{array}{c}-0.101 * * \\
(0.044)\end{array}$ & $\begin{array}{c}-0.094 * \\
(0.053)\end{array}$ & $\begin{array}{c}-0.083 \\
(0.053)\end{array}$ & $\begin{array}{c}-0.077 \\
(0.052)\end{array}$ \\
\hline Third-born & $\begin{array}{c}-0.138^{*} \\
(0.082)\end{array}$ & $\begin{array}{c}-0.132 \\
(0.086)\end{array}$ & $\begin{array}{c}-0.122 \\
(0.086)\end{array}$ & $\begin{array}{c}-0.117 \\
(0.086)\end{array}$ \\
\hline Fourth-born & $\begin{array}{c}-0.160 \\
(0.144)\end{array}$ & $\begin{array}{c}-0.155 \\
(0.144)\end{array}$ & $\begin{array}{c}-0.152 \\
(0.145)\end{array}$ & $\begin{array}{c}-0.149 \\
(0.144)\end{array}$ \\
\hline Children & 4232 & 4232 & 4232 & 4232 \\
\hline
\end{tabular}


Table 8 (continued)

(1)

(2)

(3)

$\begin{array}{ccccc}\text { Ages 11-14 } & & & & \\ \text { Second-born } & -0.194 * * * & -0.201 * * * & -0.180 * * * & -0.161 * * * \\ & (0.051) & (0.057) & (0.057) & (0.056) \\ \text { Third-born } & -0.342 * * * & -0.349 * * * & -0.333 * * * & -0.292 * * * \\ & (0.103) & (0.103) & (0.104) & (0.103) \\ \text { Fourth-born } & -0.558 * * * & -0.568 * * * & -0.558 * * * & -0.496 * * * \\ & (0.183) & (0.184) & (0.184) & (0.181) \\ \text { Children } & 3885 & 3885 & 3885 & 3885 \\ \text { Input controls } & \text { None } & \text { Birth } & \text { Pregnancy } & \text { Home } \\ & & \text { outcomes } & \text { maternal } & \text { Environment } \\ & & & \text { behavior } & \end{array}$

Notes: All regressions are weighted to account for oversampling of minorities and include family fixed effects. Standard errors clustered at the family level are in parentheses. ${ }^{*} p<0.10$, $* * p<0.05$, ${ }^{*} * *<0.01$. Sample is restricted to children with complete prenatal input information and from nontwin families. All specifications control for regional dummies, maternal age and its quadratic, gender of the child, age difference with oldest and precedent siblings, a series of cohort dummies, family income and mother's employment status year after birth (employed, unemployed, out of labor force, or in active force), mother's highest grade completed at the child's birth, presence of father figure and family size at time of assessment. Birth outcomes include flexible controls for gestational length, birth weight and length at birth, pregnancy maternal behavior includes alcohol consumption, tobacco smoking and prenatal care access; home environment includes contemporaneous and lagged measures of cognitive stimulation and emotional support.

Finally, we ask whether systematic variations in the home environment can explain early birth order differences in cognitive outcomes. Column 4 shows that controlling for home environment scores reduces the birth order effect sizes significantly. Including variations in HOME sores reduces birth order differences at ages zero to three and renders them statistically indistinguishable from zero. Although imprecisely estimated for some age groups, home environment's effect on birth order differences in cognitive outcomes is mitigated by school entrance.

These large and significant differences in early inputs and outcomes across children of varying birth order are particularly meaningful in light of growing research demonstrating the importance of early life conditions on adult outcomes. Both theoretical and empirical research on skill formation show that early childhood inputs, especially in the first five years of life, are critical in explaining future accumulation of human capital (Cunha and Heckman 2007; Heckman, Stixrud, and Urzua 2006; Heckman and Masterov 2007). Results from these studies underscore the importance of early changes in parental behavior and provide credence to our finding that systematic variations in early home environment and parental behavior can explain a large portion of the birth order differences in cognitive skills. More generally, our results suggest that a plausible explanation for the negative relation between birth order and cognitive/academic achievement is a broad change in parenting behavior and focus, especially in the 
cognitively enriching home environment that parents can provide to their first child relative to their later-born children.

\section{Conclusion}

In this paper, we show that the negative relation between birth order and educational achievement starts very early, even in the cognitive outcomes measured in the first few years of life. These early birth order effects in cognitive skills are sustained well after school entry into adolescence. Contrary to popular perception, we find that noncognitive outcomes and personalities do not appear to be systematically different by birth order, with the exception of how later-born children feel about their scholastic abilities.

To explain these early differences in cognitive achievement, we first show that there are corresponding patterns of disparities in parental behavior and in the environment that parents provide for their children at home. Although later-born children are not born disadvantaged with respect to their health or developmental markers, we find that parents are unable to provide them with the same level of cognitive support as they do with their first-born. We also find that there are systematic differences in maternal behavior during pregnancies and in the first year of children's lives. These differences indicate a broad shift in maternal attitudes and behavior toward their later-born children, before there are any strong signals of child quality. Variations in parenting styles and inputs as measured by home environment scores are able to explain most of the birth order differences in cognitive outcomes before school entrance and some of the differences post-school entry.

Taken together, our findings suggest that a plausible explanation for the negative relation between birth order and educational achievement is a broad shift in parenting, especially with respect to parents' ability to foster early cognitive development. Significant variation in parental behavior during pregnancy and in the first few years of life, as well as the absence of any differences in the quality of emotional support, are consistent with the explanation that parents are choosing to relax what they might deem as nonessential rearing needs in raising their later-born children.

For most parents, it is probably not difficult to understand how and why one's parenting focus and behaviors may change with his/her later-born children. Lessons from past experiences and additional constraints on time, resources, and attention necessitate adjustments in their attitudes and beliefs about what may be possible to accomplish as parents. These broad shifts in parental behavior appear to set later-born children on a lower path for cognitive development and academic achievement, with lasting impact on adult outcomes.

\section{References}

Anderson, Michael. 2008. "Multiple Inference and Gender Differences in the Effects of Early Intervention: A Reevaluation of the Abecedarian, Perry Preschool, and Early Training Projects." Journal of the American Statistical Association 103(484):1481-95. 
Baker, Paula C., Canada K. Keck, Frank L. Mott, and Stephen V. Quinlan. 1993. The NLSY Child Handbook 1993: A Guide and Resource Document for the NLS of Youth-Child Data. Columbus, OH: The Ohio State University, Center for Human Resource Research.

Behrman, Jere R., and Paul Taubman. 1986. "Birth Order, Schooling, and Earnings." Journal of Labor Economics 4(3):121-45.

Belfield, Clive R., and Inas Rashad Kelly. 2010. "The Benefits of Breastfeeding Across the Early Years of Childhood.” NBER Working Paper 16496, National Bureau of Economic Research, Inc.

Birdsall, Nancy. 1991. "Birth Order Effects and Time Allocation." Research in Population Economics 7:191-213.

Black, Sandra E., Paul J. Devereux, and Kjell G. Salvanes. 2005. "The More the Merrier? The Effect of Family Size and Birth Order on Children's Education." Quarterly Journal of Economics 120(2):669-700.

- 2007. "Older and Wiser? Birth Order and IQ of Young Men.” NBER Working Paper 13237, National Bureau of Economic Research.

. 2015. "Healthy(?), Wealthy, and Wise: Birth Order and Adult Health.” NBER Working Paper 21337, National Bureau of Economic Research.

Bleske-Rechek, April, and Jenna A. Kelley. 2014. "Birth Order and Personality: A Within-Family Test Using Independent Self-Reports from Both Firstborn and Later born Siblings." Personality and Individual Differences 56:15-18.

Booth, Alison L., and Hiau Joo Kee. 2009. "Birth Order Matters: The Effect of Family Size and Birth Order on Educational Attainment." Journal of Population Economics 22(2):367-97.

Brenøe, Anne A., and Ramona Molitor. 2015. "Birth Order and Health of Newborns: What Can We Learn from Danish Registry Data?" CINCH Working Paper 13.

Buckles, Kasey, and Shawna Kolka. 2014. "Prenatal Investments, Breastfeeding, and Birth Order." Social Science \& Medicine 118:66-70.

Buckles, Kasey S., and Elizabeth L. Munnich. 2012. "Birth Spacing and Sibling Outcomes." Journal of Human Resources 47(3):613-42.

Cunha, Flavio, and James J. Heckman. 2007. "The Economics of Human Development: The Technology of Skill Formation." The American Economic Review 97(2):31-47.

- 2008. "Formulating, Identifying and Estimating the Technology of Cognitive and Noncognitive Skill Formation." Journal of Human Resources 43(4):738-82.

Currie, Janet, and Jeffrey Grogger. 2002. "Medicaid Expansions and Welfare Contractions: Offsetting Effects on Prenatal Care and Infant Health?" Journal of Health Economics 21(2): 313-35.

De Haan, Monique, Erik Plug, and José Rosero. 2014. "Birth Order and Human Capital Development Evidence from Ecuador." Journal of Human Resources 49(2):359-92.

Deming, David. 2009. "Early Childhood Intervention and Life-Cycle Skill Development: Evidence from Head Start." American Economic Journal: Applied Economics 1(3):111-34.

Ejrnæs, M., and Claus C. Pörtner. 2004. "Birth Order and the Intrahousehold Allocation of Time and Education." Review of Economics and Statistics 86(4):1008-19.

Fingerhut, L.A., J.C. Kleinman, and J.S. Kendrick. 1990. "Smoking Before, During, and After Pregnancy." American Journal of Public Health 80(5):541-4.

Fryer, Ronald, and Steven Levitt. 2004. "Understanding the Black-White Test Score Gap in the First Two Years of School." Review of Economics and Statistics 86(2):447-64.

Hanushek, Eric A. 1992. “The Trade-off between Child Quantity and Quality.” Journal of Political Economy 100(1):84-117.

Heckman, James J., and Dmitri V. Masterov. 2007. "The Productivity Argument for Investing in Young Children." Applied Economic Perspectives and Policy 29(3):446-93.

Heckman, James J., Jora Stixrud, and Sergio Urzua. 2006. "The Effects of Cognitive and Noncognitive Abilities on Labor Market Outcomes and Social Behavior." Journal of Labor Economics 24(3):411-82. 
Hofferth, Sandra L. 2009. "Changes in American Children's Time-1997 to 2003." Electronic International Journal of Time Use Research 6(1):26-47.

Horwood, L. John, and David M. Fergusson. 1998. "Breastfeeding and Later Cognitive and Academic Outcomes." Pediatrics 101(1):e9.

Hotz, V. Joseph, and Juan Pantano. 2015. "Strategic Parenting, Birth Order and School Performance." Journal of Population Economics 28(4):911-36.

Juhn, Chinhui, Yona Rubinstein, and C. Andrew Zuppann. 2015. "The Quantity-Quality Tradeoff and the Formation of Cognitive and Non-cognitive Skills." Working Paper 21824, National Bureau of Economic Research.

Kantarevic, Jasmin, and Stéphane Mechoulan. 2006. "Birth Order, Educational Attainment, and Earnings." Journal of Human Resources 41(4):755-77.

Kessler, Daniel. 1991. "Birth Order, Family Size, and Achievement: Family Structure and Wage Determination." Journal of Labor Economics 9(4):413-26.

Kilburn, Tina R., Hanne-Lise Falgreen Eriksen, Mette Underbjerg, Poul Thorsen, Erik Lykke Mortensen, Nils Inge Landrø, Leiv S. Bakketeig, Jakob Grove, Claus Sværke, and Ulrik Schiøler Kesmodel. 2015. "Low to Moderate Average Alcohol Consumption and Binge Drinking in Early Pregnancy: Effects on Choice Reaction Time and Information Processing Time in Five-Year-Old Children." PLoS ONE 10(9):e0138611.

Kling, Jeffrey R., Jeffrey B. Liebman, and Lawrence F. Katz. 2007. "Experimental Analysis of Neighborhood Effects." Econometrica 75(1):83-119.

Lang, Kevin, and Carlos E. Sepulveda. 2007. "The Black-White Test Score Differential.” Boston University Working Paper.

Lewis, Caroline T., T.J. Mathews, and Robert L. Heuser. 1996. "Prenatal Care in the United States, 1980-94." Vital and Health Statistics. Series 21, Data on Natality, Marriage, and Divorce 54. Washington, DC: National Center for Health Statistics

Monfardini, Chiara, and Sarah Grace See. 2016. "Birth Order and Child Cognitive Outcomes: An Exploration of the Parental Time Mechanism." Education Economics 24(5):481-95.

Mott, Frank L. 1991. "Developmental Effects of Infant Care: the Mediating Role of Gender and Health." Journal of Social Issues 47(2):139-58.

Oddy, Wendy H., Garth E. Kendall, Eve Blair, Nicholas H. De Klerk, Fiona J. Stanley, Louis I. Landau, Sven Silburn, and Stephen Zubrick. 2003. "Breastfeeding and Cognitive Development in Childhood: A Prospective Birth Cohort Study." Paediatric and Perinatal Epidemiology 17(1):81-90.

Parish, William L., and Robert J. Willis. 1993. "Daughters, Education, and Family Budgets Taiwan Experiences." Journal of Human Resources 28(4):863-98.

Pavan, Ronni. 2016. "On the Production of Skills and the Birth Order Effect." Journal of Human Resources 51(3):699-726.

Price, Joseph. 2008. "Parent-Child Quality Time." Journal of Human Resources 43(1):240-65.

Romano, Joseph P., and Michael Wolf. 2005. "Stepwise Multiple Testing as Formalized Data Snooping." Econometrica 73(4):1237-82.

Ross, Catherine E., and Beckett A. Broh. 2000. "The Roles of Self-Esteem and the Sense of Personal Control in the Academic Achievement Process." Sociology of Education 73(4):270-84.

Rothstein, Donna S. 2013. "Breastfeeding and Children's Early Cognitive Outcomes." Review of Economics and Statistics 95(3):919-31.

Skogerb $\varnothing$, Å, U.S. Kesmodel, T. Wimberley, H. Støvring, J. Bertrand, N.I. Landrø, and E.L. Mortensen. 2012. "The effects of low to moderate alcohol consumption and binge drinking in early pregnancy on executive function in 5-year-old children." BJOG 119:1201-1210.

Todd, Petra E., and Kenneth I. Wolpin. 2007. "The Production of Cognitive Achievement in Children: Home, School, and Racial Test Score Gaps.” Journal of Human Capital 1(1):91-136.

Zajonc, Robert B. 1976. "Family Configuration and Intelligence: Variations in Scholastic Aptitude Scores Parallel Trends in Family Size and the Spacing of Children.” Science 192(4236):227-36. 